\title{
Study of Steel Electro-dissolution Behavior in Presence of Some Surfactants. Electrochemical Investigation and Surface Active Properties Determination
}

\author{
FATMA. M. ABOUZEID* \\ Chemistry Department, Faculty of Science, Alexandria University, Alexandria, Egypt
}

\begin{abstract}
Steel electro-dissolution performance was investigated in orthophosphoric acid in the presence of N-oleyl 1.3 Diaminopropane, Benzalkounuim chloride, Soduim Lauryl sulphate and Di-Isononyl phthalate as a surfactant using potentiodynamic polarization measurements. The retardation performance of these surfactants was examined. The surfactant surface active parameters were estimated based on surface tension measurements. The parameters calculated comprise the critical micelle concentration (CMC), maximum surface excess (Гmax), minimum surface area (Amin) and effectiveness $(\pi C M C)$. The micellization thermodynamic parameters ( $\triangle \mathrm{Gmic}, \Delta S \mathrm{Smic})$ for the estimated surfactants were also computed. Results obtained from surface active properties are comparable with those gained from galvanostatic polarization measurements. Temperature influence on the steel dissolution performance was examined at 25 to $40^{\circ} \mathrm{C}$ range. Steel kinetic study in orthophosphoric acidfree solution and orthophosphoric acid containing surfactant was also examined. The dissolution kinetic and activated parameters were computed. Results based on microscopy measurement indicate that, addition of new four surfactants, resulting in the solution shows potential, a discrete progress in the metal texture was monitored. Improvement produced in electro-polishing bath by the investigated SAS that owing to the adsorption of such surface active agents on the anode surface
\end{abstract}

Kwywords: C-steel, electro-dissolution, scanning electron microscope (SEM), surfactant, surface active properties

\section{Introduction}

Electro-polishing is extensively working in manufacturing for micro finishing and deburring of dissimilar metallic constituents. A great quantity of electrolytic baths with diverse working circumstances and electrolyte compositions are estimated for long time [1]. Regardless of greatly progression in the metals science and technology field, the metals corrosion phenomenon stays a main apprehension to industry about the planet. Electro-polishing is the technique of electrolytic metal finishing, presently broadly used in numerous elevated functions like cardiovascular and orthopedic body implants, pharmaceutical and semiconductor installations.

Amongst furthers, the technique offers an extremely clean, even and smooth resistant exterior. Presently, approximately any metal, alloy and inter metallic compound may be electro-polished [2] .The importance of electro polishing on surface of metal process mainly is for the metals treatment and alloys to improve luminous surface finishes with very low surface roughness values, no residual surface tensions and improved steel resistance to deterioration [3].

Steel electro-dissolution provides the surface homogenization, and thus the generation of a high degree of shine as well as the de-burring of cut and punched edge [4],noting that steel has found a broad applications in a wide industrial field and equipment as it is extensively used on cutting tools, forging and punching dies also steel usually utilized in edifice materials for pipelines in the oil and gas industry but they are very vulnerable to together a grand common dissolution rate and strict localized dissolution but steel has a propensity for corrosion, which is a essential industrial apprehension that has received a significant quantity of awareness due to its superior harden ability, improved wear confrontation and appropriate stoutness [5].

*email: fatma.abouzeid@yahoo.com 
The phenomenon of metals dissolution stay a chief worry to industries in the world, so inhibitors are usually applied to defend metal from deterioration.

The selection of most favorable inhibitor ought to be based on three reflections:

(a) It should have a suitable production of economical rare resources.

(b) The incidence of hetero atom like nitrogen, oxygen, sulfur and multiple bonds in the inhibitor molecule is necessitated for its effectiveness.

(c) Its should be environmentally friendly [6].

It is usually believed that bulk organic compounds retard dissolution through the metal-solution interface adsorption [7]. Where two main adsorption methods of chemical or physical are correlated to organic molecules control firstly via overcrowding the reaction sites or creating a physical obstruction to decrease the corrosion species diffusion to metal surface.

On basis that the adsorption mode is reliant on the subsequent features: concentration of inhibitor, interface electrochemical potential, metal nature and metal surface charge, surface chemistry, solution chemistry and dissolution reaction temperature

Temperature has a immense influence on the metal dissolution rate and its distinction is an important factor for investigating and descriptive the steel electro polishing and inhibitor adsorption mechanism.

Electro- dissolution was carried out in the limiting-current anodic polarization curve plateau, at which anodic dissolution was below mass-transfer management. Conversely, the classes prevailing the mass-transfer management is significantly metal electrode and electrolyte dependent [8].

However, some work shows to have been done on the steel corrosion inhibition in $\mathrm{H}_{3} \mathrm{PO}_{4}$. The corrosion of steel in phosphoric acid was investigated earlier in the presence of gelatin [9], lactic and mandolic Acid [10], natural products [11,12], some drugs[13], urea, thiourea, triethanolamine, FINEAMIN 88 and FINEAMIN 06 [14], 6-methyl-7H-1,2,4triazolo[4,3-b][1,2,4]-triazepine-8(9H)thione [15] , Eucalyptus leaf extract [16]. Therefore, the goal of this research is to investigate the steel dissolution behavior in $\mathrm{H}_{3} \mathrm{PO}_{4}$ in existence of contemptible, environmentally friendly and simple produced surfactants. In our research study, potentiodynamic polarization technique was carried out to inspect the steel electro-dissolution in the presence of N-oleyl 1.3 diaminopropane and Di-Isononyl phthalate as nonionic surfactant, Benzalkounuim chloride as cationic surfactant, Soduim lauryl sulphate as an anionic surfactant. The surfac active parameters of each investigated surfactant (SAS) were estimated (from its surface tension outline) to compare the inhibitors retardation efficiency with their surface active parameters

\section{Materials and methods}

The electrolyte solution was prepared from analar grade of $\mathrm{H}_{3} \mathrm{PO}_{4}(85 \% \mathrm{w} / \mathrm{w})$ supplied by $\mathrm{BDH}$ Chemicals Ltd. The selected non-ionic, anionic and cationic surfactants (Figure 1) were of clean excellence $(>97 \%)$ and utilized without further purification. de-mineralized water was utilized in the solution preparation.

\section{Solution preparation}

$8 \mathrm{M} \mathrm{H}_{3} \mathrm{PO}_{4}$ and different concentrations range of surfactant $\left(1 \times 10^{-4}-1 \times 10^{-3} \mathrm{M}\right)$ has been prepared.

\section{Analysis of carbon steel specimen composition (weight \%)}

The composition of the steel electrodes used in electro-polishing was made in the Egyptian company for cupper, it is important as the metals present in the electrode alloy effects the rate of the process and the enhancement or inhibition rate in presence of the surfactants, the analysis of the steel specimen of the electrode in weight $\%$ is as follows:

$$
\text { C (0.2\%), S (0.04\%), Mn (2.6\%), P (0.039\%), Si (0.36), Fe (96.761\%) }
$$




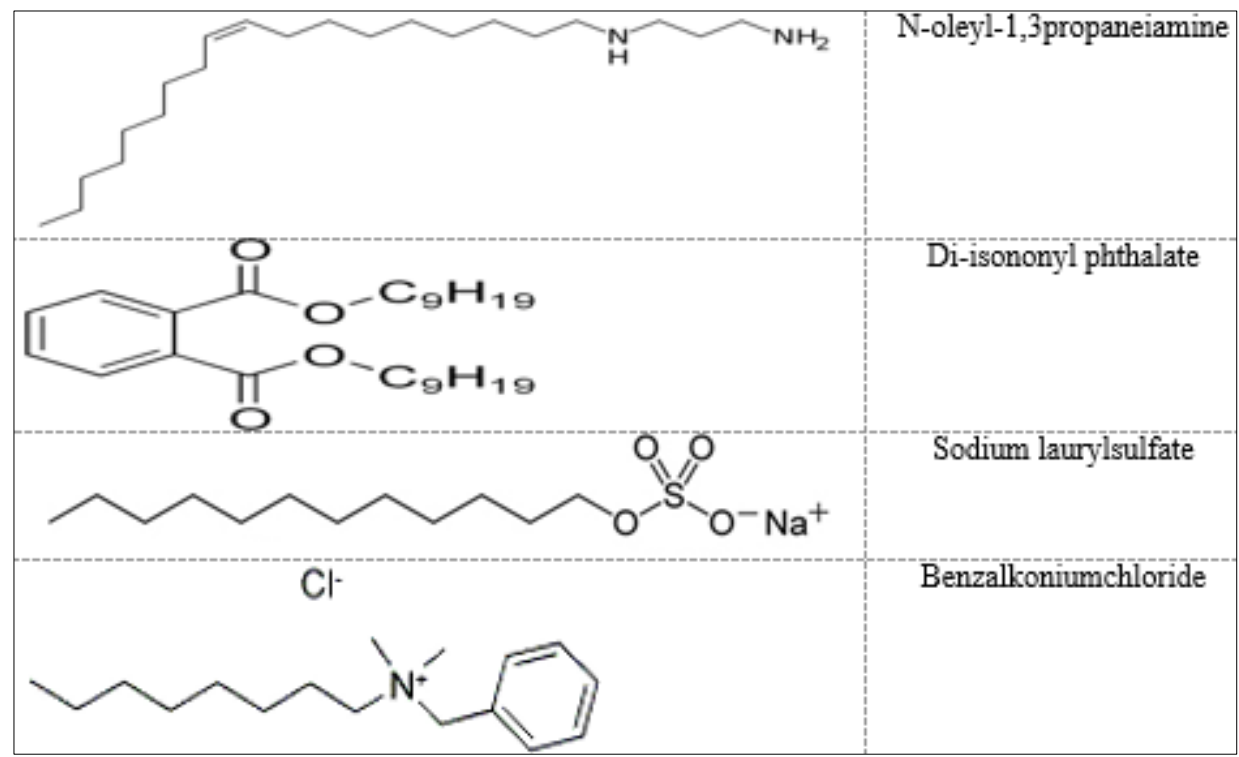

Figure 1. Structure of surfactants

\section{Surface tensionanalysis}

The surface tension was investigated at $20,30,40$ and $50^{\circ} \mathrm{C}$ using Du Nouytensiometer (Kruss type $8451)$. The temperature $\left( \pm 0.1^{\circ} \mathrm{C}\right)$ was reserved stable by flow the thermostatic water via a jacketed craft -containing solution. The solution concentration was diverse by adding stock solution aliquots of identified concentration to the identified volume of the vessel solution.

\section{Scanning electron microscope}

(JEOL, JSM-5300, scanning microscope, OXFORD instrument) has been used in order to investigate steel surface qualitatively.

\section{Results and discussions}

\section{Surface active possessions}

\section{Determination of SAS CMC in $8 \mathrm{M} \mathrm{H}_{3} \mathrm{PO}_{4}$}

The major CMC implication based on fact, at this concentration, the majority of the surfactant physical and chemical properties present an unpredicted difference.[17]The surface tension values $(\gamma$, $\mathrm{mN} / \mathrm{m}$ ) for the four SAS under examination were schemed versus the logarithm of the SAS concentration $(\log C)$ at several temperatures as represented in Figure 2 The critical micelle concentration(CMCs), for the investigated SAS were concluded from the spot of interrupt of the two linear parts gained through the $\gamma-\log C$ plots. The reproducibility of the surface tension versus concentration curve was confirmed via carrying out at least three separate trials. It is obvious that, the surface tension decreases via raising the concentration until CMC is arrived, above which the surface tension is not influenced by a more SAS concentration addition, CMCs for the four SAS are listed in (Table 1) [18].

Table 1. Variation of CMC for the surfactants at different temperatures in $8 \mathrm{M} \mathrm{H}_{3} \mathrm{PO}_{4}$

\begin{tabular}{|c|c|c|c|c|}
\hline Surfactant & $\mathbf{2 0}^{\circ} \mathbf{C}$ & $\mathbf{3 0}^{\circ} \mathbf{C}$ & $\mathbf{4 0}^{\circ} \mathbf{C}$ & $\mathbf{5 0}^{\circ} \mathbf{C}$ \\
\hline Diisononylphtalate & $\mathbf{4 x 1 0}^{-4}$ & $\mathbf{5 \times 1 0 ^ { - 4 }}$ & $\mathbf{7 \times 1 0 ^ { - 4 }}$ & $\mathbf{8 \times 1 0 ^ { - 4 }}$ \\
\hline N-oleill.3diamino propane & $\mathbf{3 \times 1 0 ^ { - 4 }}$ & $\mathbf{4 \times 1 0 ^ { - 4 }}$ & $\mathbf{6 \times 1 0 ^ { - 4 }}$ & $\mathbf{7 x 1 0}^{-4}$ \\
\hline Sodium lauryl sulphate & $\mathbf{5 x 1 0}^{-4}$ & $\mathbf{6 \times 1 0}$ & $\mathbf{7 x 1 0}^{-4}$ & $\mathbf{9 x 1 0}^{-4}$ \\
\hline Benzalkonium chloride & $\mathbf{6 \times 1 0 ^ { - 4 }}$ & $\mathbf{7 \times 1 0 ^ { - 4 }}$ & $\mathbf{8 x 1 0}^{-4}$ & $\mathbf{1 0 \times 1 0}^{-4}$ \\
\hline
\end{tabular}

From Figure 2 it was found that reduce in surface tension is monitored while the SAS concentration enlarges and then stays constant at fixed point where further addition would have no effect on surface tension indicating that, point at which CMC takes place at all temperature. 


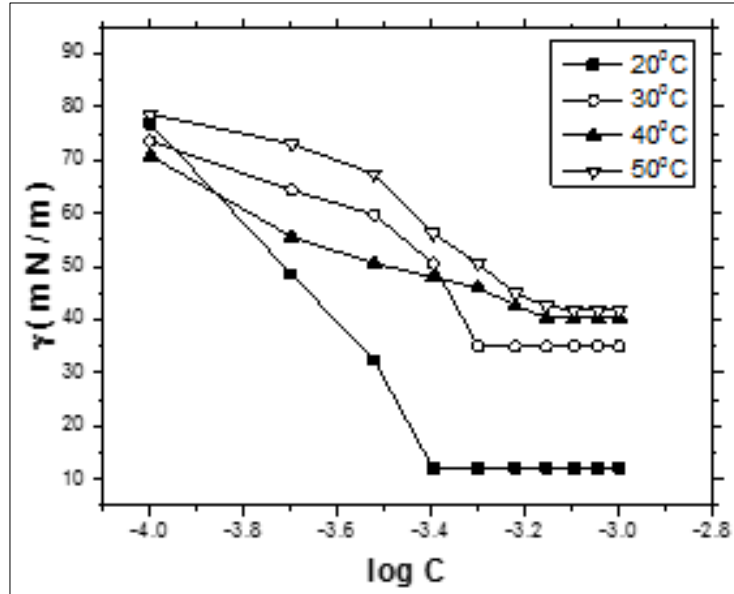

a

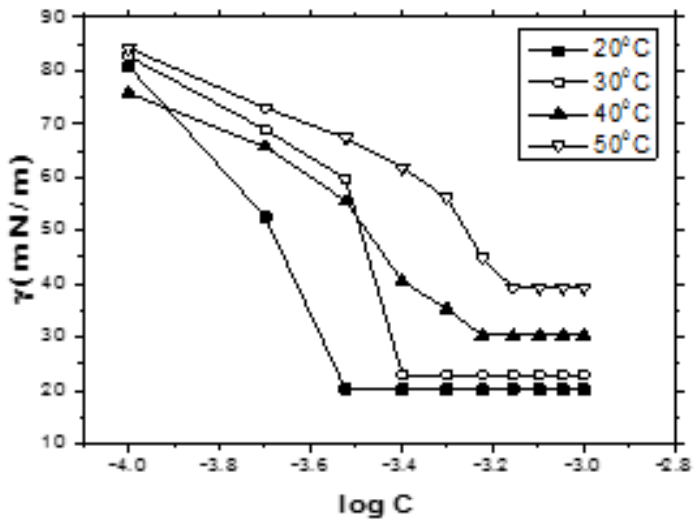

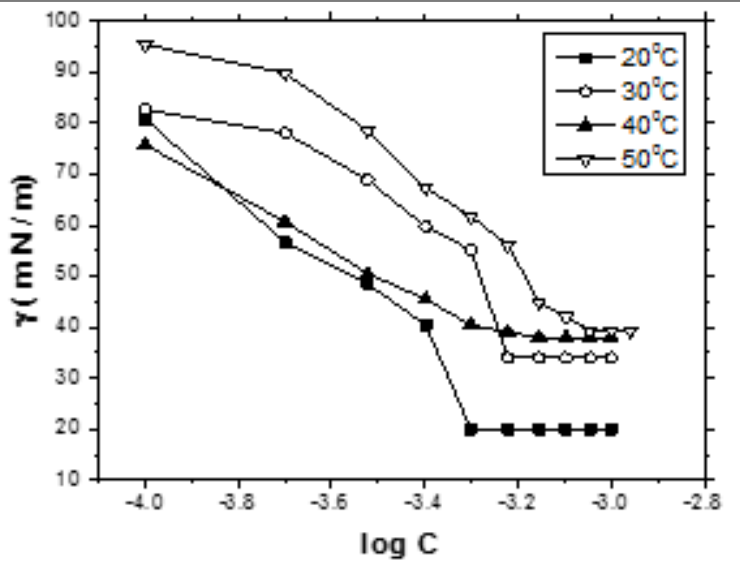

$\mathrm{b}$

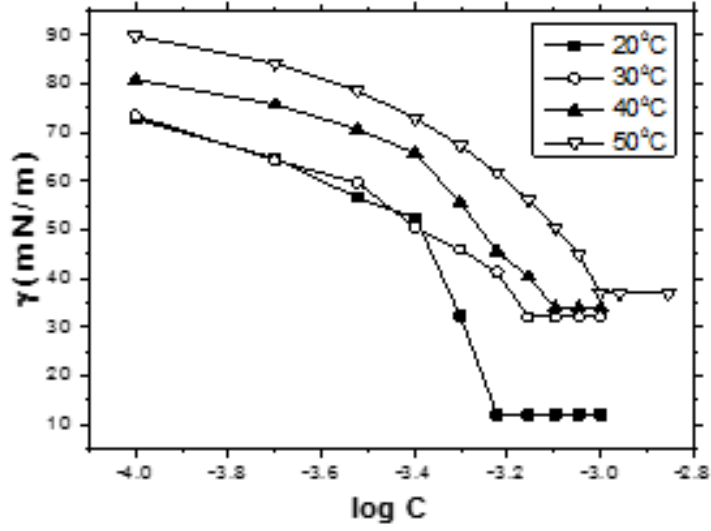

d

Figure 2. Relation between surface tension and $\log \mathrm{C}$ at different temperature in $8 \mathrm{M} \mathrm{H}_{3} \mathrm{PO}_{4}$ of a) Diisononyl phthalate, b) N-oleil1.3diaminopropane c) Sodium lauryl sulphate and d) Benzalkonium chloride

In general, Sodium lauryl sulphate and Benzalkonium chloride (ionic surfactants), have higher CMC than n-oleil1.3diamino propane and Diisononyl phthalate (nonionic surfactant). This can be attributed to the fact that, the free energy required to bring the polar heads of the surfactant collectively in case of nonionic surfactant when the head group is uncharged the CMC is usually smaller than that when the heads is charged in ionic surfactant [19].

From Table (1) it was found that in case of Benzalkonium chloride it has the highest CMC at all temperatures that's can be explained as follows, for ionic surfactants with charged heads possess a higher CMC than that of nonionic surfactant as the head groups causes a steric repulsions between the similar charges of the surfactant so repulsion can be supposed to augment as the positively charged nitrogen atom number increases , and the higher CMC can be attributed to small hydrophobic alkyl tail of Benzalkonium chloride and the presence of the benzene ring and it's orientation were found to increases the CMC value in this study [20].

For Sodium lauryl sulphate surfactants it has CMC higher than nonionic surfactant in this study due to the repulsion force between the similarly charged heads as mentioned before as well with increasing the sulphate groups gives rise to raise in the $\mathrm{CMC}$ as the head group size raises. For a certain ethylene oxide chain length and an equilibrium packing parameter matching to globular micelles, raising the chain length of the surfactant tail will result in increasing in the aggregation number. In this study Sodium lauryl sulphate has $\mathrm{CMC}$ lower than that of Benzalkonium chloride that may be attributed to long alkyl 
chain of Sodium lauryl sulphate and the steric hindrance caused by the benzene ring, it's orientation and the small alkyl chain of Bezalkonium chloride [21].

Diisononyl phthalate possess a higher CMC than that of n-oleil 1.3diamino propane due to the presence of the benzene ring as mentioned above and as Diisononyl phthalate is considered as a double tail surfactant and if single and double tail surfactant particles are contrasted, for the same equilibrium region per molecule, the doublly tailed molecule will have an aggregation number two times as large as that of the singly tailed molecule. Hence, the doubly tailed molecules can self-accumulate to form bilayer vesicles whereas the equivalent single tail molecule aggregates into only sphere-shaped micelles [22]. In addition to that the steric hindrance possessed by the benzene ring and its orientation will also have a great effect on the unexpected raise in its CMC. For an ionicsurfactants with ethylene oxide as the head group in Diisononyl phthalat, the steric repulsions between the head groups can be supposed to enlarge the number of ethylene oxide units in a head group. In common evaluate ionic and nonionic surfactants, the head group interaction will be larger for the ionic surfactant than for the nonionic owing to one has to also regard as ionic repulsions among the head groups therefore compared to nonionic surfactants of the same tail length , an enhance in the CMC when ionic and nonionic surfactants of equal tail lengths are compared.

In the case there is no charged head group, surfactant mange to form micelles via the hydrophobic force and Vander Waals interaction. The strong communication among water molecules ward off the hydrocarbon chain out off the water bulk phase [23]. This forces the surfactants to summative forming micelle, where the hydrophilic head groups pointed to the water covering the hydrocarbon tail. Micelle configuration is consequently predictable to occur at inferior concentration for non-ionic surfactant in comparable with ionic surfactants. For ionic surfactants, elevated concentrations are essential to get rid of the electrostatic repulsion among ionic charged head groups through the micelle arrangement process.

\section{Effect of electrolyte}

The CMC is affected by some factors including the nature of SAS and the aqueous electrolyte used. $\mathrm{HPO}_{4}{ }^{2-}$ presence in the electro polishing cell is one of the main features being accountable for the alteration of the CMC values in comparison with their original values in uncontaminated water. These phenomenon are attributed to the famous Hofmeister sequence, that is an pragmatic quantify the ions hydration degree. The Hofmeister sequence arranges ions as raised salting in strength from left to right as in the subsequent:

$$
\mathrm{SO}_{4}^{-2}, \mathrm{HPO}_{4}^{-2}, \mathrm{OH}^{-}, \mathrm{HCOO}^{-}, \mathrm{CH}_{3} \mathrm{COO}^{-}, \mathrm{Cl}^{-}, \mathrm{Br}^{-}, \mathrm{NO}_{3}^{-}, \mathrm{I}^{-}, \mathrm{SCN}^{-}, \mathrm{ClO}^{-}
$$

$\mathrm{HPO}_{4}{ }^{-2}$ is situated to the left side of chloride ion $\left(\mathrm{Cl}^{-}\right.$represents in some way, a intermediate with the Hofmeister sequence) acts as water structure creators (salting out ions) or (cosmotropicions). The salting out influence is take place when $\mathrm{HPO}_{4}^{-2}$ competing with surfactant for hydration water, diminishes the water amount obtainable in the micelles for polar chain hydration. Consequently micelle configuration will be constructed at a low surfactant concentration [24,25].

There may be another explanation in case of Diisononyl phthalate and $\mathrm{N}$-oleil1.3diamino propane which is the formation of hydrogen link with water molecules through the oxyethylene component in case of Diisononyl phthalate and the $\mathrm{N}$ atom of $\mathrm{N}$-oleil1.3diamino propane required high energy to break, to enable surfactant aggregation, thus the micelles formation occurred at elevated concentration in contrast to in $8 \mathrm{M} \mathrm{H}_{3} \mathrm{PO}_{4}$, no hydrogen bond will be formed so the ability of Diisononyl phthalateand $\mathrm{N}$-oleil1.3diamino propane molecules to form micelle will be enhanced and shaped at low concentration than through water [26]. Whilst in sodium lauryl sulphate and Benzalkonium chloride case, a decrease in the electrostatic repulsion force among anionic hydrophilic head group and as a result, a lesser influence of repulsion which decreases the efficiency of micelle formation takes place. So, in $8 \mathrm{M} \mathrm{H}_{3} \mathrm{PO}_{4}$, SDS begins micelles formation in easy way and causes CMC of Sodium lauryl sulphate and benzalkonium chloride to be lower than that of distilled water [27]. 


\section{Effect of temperature}

A network of cations and anions interaction in ionic liquids are considered and not only by means of electrostatic forces other than forming comprehensive hydrogen bond associations also [28,29]. In another interpretation, supra molecular structure of surfactant results in solvent-solute communication, temperature elevation may results in some modification between the contact affecting the final consequence. Also, the number of comparatively feeble hydrogen and vander Waals interactions among surfactant molecules becomes diminished. Thus, the surfactants solvophobicity is augmented, favoring micellization process to happen at elevated surfactant concentration.

The attained $\mathrm{CMC}$ values demonstrate an raising tendency through rising temperature (Table 1). The raise in temperature results in reduction the hydrophilic group hydration (which favors micelles formation) or causes disturbance in the structural of water molecules adjoining the hydrophobic group (that effect that is not preferred micellization). The comparative scale of these two opposite effects, so, determines if the CMC amplifies or diminishes over a desired temperature range. The data in Table1 indicates that $\mathrm{CMC}$ augments by increasing temperature which indicates that both aspects enormity is not prefer micelle formations [30, 31].

\section{Surface active parameters}

The pure surfactant surface active possessions are effectiveness $(\pi \mathrm{cmc})$, maximum surface excess $\left(\Gamma_{\max }\right)$, and minimum area per molecule $\left(\mathrm{A}_{\min }\right)$ were computed via the subsequent equations:

$$
\begin{aligned}
& \pi_{\mathrm{cmc}}=\gamma_{\mathrm{o}}-\gamma_{\mathrm{cmc}} \\
& \Gamma_{\max }=1 / 303 \mathrm{RT} \quad{ }_{-\mathrm{o}} \gamma /_{\mathrm{s}} \log \mathrm{C} \\
& \text { Amin }=10^{16} /\left[\Gamma_{\max } \cdot \mathrm{NA}\right]
\end{aligned}
$$

where $\gamma_{\mathrm{o}}$ is the pure water surface tension measured, $\gamma_{\mathrm{cmc}}$ is the surface tension at CMC $(\mathrm{mN} / \mathrm{m})$. The surfactant molecules concentration at the interface for each unit area is expressed as $\left(\Gamma_{\max }, \mathrm{mol} \mathrm{cm}^{-2}\right), \mathrm{T}$ is the absolute temperature, $\mathrm{R}$ is the molar gas constant $(\mathrm{R}=8.314 \mathrm{~J} / \mathrm{mol} . \mathrm{K}), \mathrm{C}$ is the surfactant concentration (mol/L). NA is the Avogadros number $\left(6.023 \times 10^{23}\right.$ molecule $\left./ \mathrm{mol}\right)$.

The micellization thermodynamic parameter articulated via standard free energy $\Delta \mathrm{Gmic}$ and micellization entropy $\Delta$ Smic are computed from the equations:

$$
\begin{aligned}
& \Delta \mathrm{G}_{\text {mic }}=\mathrm{RT} \ln \mathrm{CMC} \\
& \Delta \mathrm{S}_{\text {mic }}=\left(-\delta \Delta \mathrm{G}_{\text {mic }} / \delta \mathrm{T}\right)
\end{aligned}
$$

$\Gamma_{\max }$ is calculated from the slop of $\gamma-\log \mathrm{C}$ plots fig 6 .and the surface active parameters values are listed in Table 2, $\Delta S_{\text {mic }}$ is estimated from the slop of $T-\Delta G_{\text {mic }}$ plot Figure 3 [32]

From Table 2, it is obvious that the slighter $\Gamma_{\max }$, and the higher $\mathrm{A}_{\min }$ is recorded for $\mathrm{N}$-oleyl 1.3diaminopropanerelative to Benzalkounuim chloride, Soduim lauryl sulphate and Di-Isononyl phthalate respectively.

It is obvious that $A_{\text {min }}$ increases as the temperature enlarges. This is may be characteristic to the gradual increase in thermal motion.

The $\pi_{\mathrm{cmc}}$ values indicate that $\mathrm{N}$-oleyl 1.3 diamino propane has the most effectiveness among the four surfactants due to the large decrease in surface tension which takes place at the CMC of N-oleyl 1.3diaminopropane that's why it has the largest inhibition efficiency on dissolution process followed by Benzalkounuim chloride, Soduim lauryl sulphate and Di-Isononyl phthalate respectively [33]. 
Table 2. Surface active parameters value of the four studied surfactants

\begin{tabular}{|c|c|c|c|c|c|c|c|c|}
\hline Parameters & Temperature & $\begin{array}{c}10^{4} \mathrm{CMC} \\
\mathrm{mol} / \mathrm{L}\end{array}$ & $\begin{array}{c}\gamma_{\mathrm{CMC}} \\
(\mathrm{mN} / \mathrm{m})\end{array}$ & $\begin{array}{c}\Gamma \times 10^{10} \\
\left(\mathrm{~mol} / \mathrm{cm}^{2}\right)\end{array}$ & $\begin{array}{c}\text { Л } \begin{array}{c}\text { UCMC } \\
(\mathrm{mN} / \mathrm{m})\end{array}\end{array}$ & $\begin{array}{l}A_{\min } \\
\left(A^{2}\right)\end{array}$ & $\begin{array}{c}-\Delta \mathrm{G}_{\text {mic }} \\
(\mathrm{kJ} / \mathrm{mol})\end{array}$ & $\begin{array}{c}-\Delta S_{\text {mic }} \\
(\mathrm{kJ} / \mathrm{mol} . \mathrm{K})\end{array}$ \\
\hline \multirow[t]{4}{*}{ Diisononyl phthalate } & $20^{\circ} \mathrm{C}$ & 4 & 20.22 & 2.2 & 51.78 & 75.36 & 19.1 & \multirow[t]{4}{*}{0.59} \\
\hline & $30^{\circ} \mathrm{C}$ & 5 & 35 & 1.5 & 37 & 110.72 & 18.5 & \\
\hline & $40^{\circ} \mathrm{C}$ & 7 & 40.33 & 1.03 & 31.67 & 161.92 & 17.7 & \\
\hline & $50^{\circ} \mathrm{C}$ & 8 & 41.7 & 0.86 & 30.3 & 193.27 & 17.4 & \\
\hline \multirow{4}{*}{$\begin{array}{c}\mathrm{N} \text {-oleil1.3 } \\
\text { diaminopropane }\end{array}$} & $20^{\circ} \mathrm{C}$ & 3 & 12.13 & 1.2 & 59.87 & 135.58 & 19.8 & \multirow[t]{4}{*}{0.73} \\
\hline & $30^{\circ} \mathrm{C}$ & 4 & 22.98 & 1 & 49.02 & 166.08 & 19.1 & \\
\hline & $40^{\circ} \mathrm{C}$ & 6 & 25.28 & 0.87 & 46.72 & 190.62 & 18.1 & \\
\hline & $50^{\circ} \mathrm{C}$ & 7 & 28.08 & 0.82 & 43.92 & 203.37 & 17.7 & \\
\hline \multirow{4}{*}{$\begin{array}{l}\text { Sodium lauryl } \\
\text { sulphate }\end{array}$} & $20^{\circ} \mathrm{C}$ & 5 & 20 & 1.9 & 52 & 89.56 & 18.5 & \multirow[t]{4}{*}{0.46} \\
\hline & $30^{\circ} \mathrm{C}$ & 6 & 34 & 1.04 & 38 & 159.66 & 18.1 & \\
\hline & $40^{\circ} \mathrm{C}$ & 7 & 38 & 9.04 & 34 & 183.75 & 17.7 & \\
\hline & $50^{\circ} \mathrm{C}$ & 9 & 39.32 & 8.23 & 32.68 & 201.73 & 17.1 & \\
\hline \multirow{4}{*}{$\begin{array}{l}\text { Benzalkonium } \\
\text { chloride }\end{array}$} & $20^{\circ} \mathrm{C}$ & 6 & 14 & 1.4 & 58 & 118.73 & 18.1 & \multirow[t]{4}{*}{0.42} \\
\hline & $30^{\circ} \mathrm{C}$ & 7 & 32.17 & 1.03 & 39.83 & 160.54 & 17.7 & \\
\hline & $40^{\circ} \mathrm{C}$ & 8 & 34 & 0.88 & 38 & 189.03 & 17.4 & \\
\hline & $50^{\circ} \mathrm{C}$ & 10 & 37 & 0.82 & 35 & 201.97 & 16.8 & \\
\hline
\end{tabular}

From Table 2 it`s apparent that from thermodynamic parameters of micelle formation, we can deduce that micelle formation process is spontaneous process $(\Delta \mathrm{Gmic}<0)[34]$. The $\Delta \mathrm{G}_{\text {mic }}$ value for $\mathrm{N}$-oleyl 1.3diaminopropaneis more negative in comparison with Di-Isononyl phthalate, Soduim lauryl sulphate and Benzalkounuim chloride respectively that observation indicates which surfactant can form micelle more easily than the others, the order according to how easy the surfactant can form micelles according to the free energy consideration is N-oleyl 1.3diaminopropane $>$ Di-Isononyl phthalate $>$ Soduiml auryl sulphate $>$ Benzalkounuim chloride that results come with agreement with the values of the CMC estimated for each one in the Table 4, where CMC of N-oleyl 1.3diaminopropaneis less than that of DiIsononyl phthalate, Soduimlauryl sulphate and Benzalkounuim chloride.

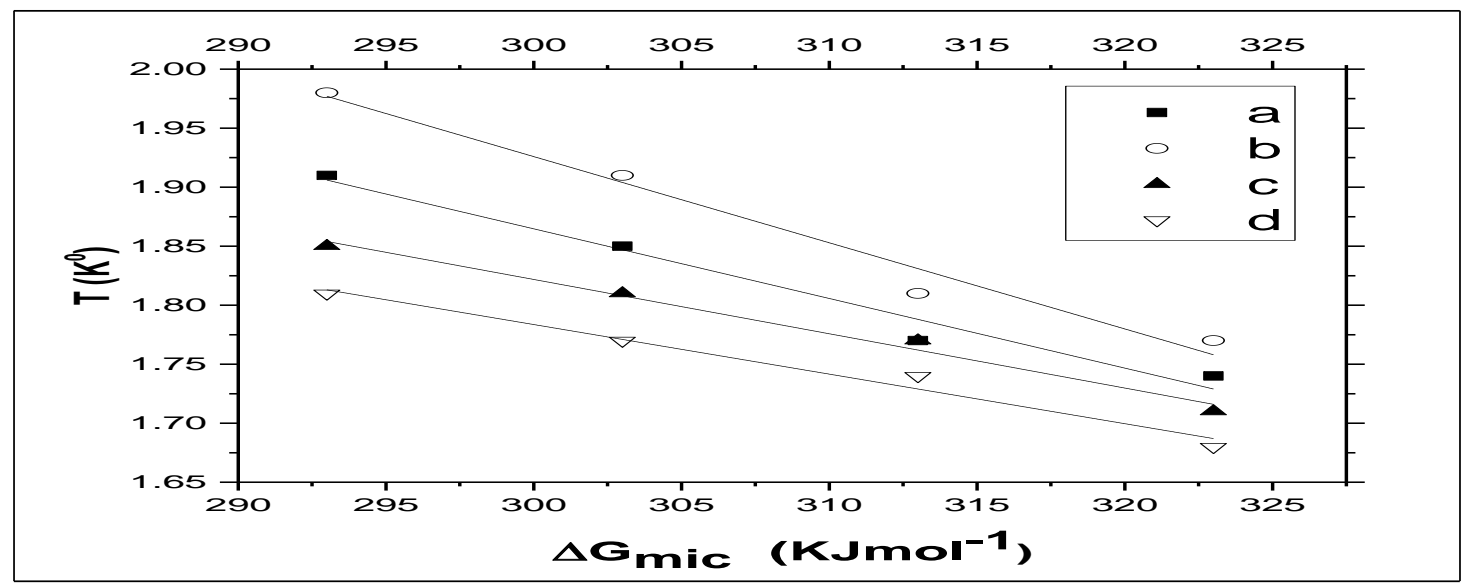

Figure 3. Relation between $\mathrm{T}$ and $\Delta \mathrm{G}_{\mathrm{mic}}$ of a) isononyl phthalate,

b) n-oleyl 1.3di aminopropane, c) sod.laurylsulphate, d) benzalkonium chloride

From Table 2 it`s apparent that $\Delta \mathrm{G}_{\text {mic }}$ values for each surfactant undergo reduction with increasing temperature so values of $\mathrm{CMC}$ increases as the temperature increases and that's come with agreement with the estimated data of the CMC in the Table 2 at different temperature [35]. $\Delta \mathrm{S}_{\text {mic }}$ possess positive value from the data estimated from the Table 2 it was found that the order of positive value from high to low is as following $\mathrm{N}$-oleyl 1.3diaminopropane $>$ Di-Isononyl phthalate $>$ Soduim laurylsulphate 
$>$ Benzalkounuim chloride indicating that the randomness of the system increases during surfactant molecules alteration into micelle.

\section{Polarization curves}

Figure 4 demonstrates the polarization curves and current density for the steel anodization in orthophosphoric acid at several concentrations of the four studied SAS ranging from $1 \times 10^{-4}$ to1 $\times 10^{-3}$ $\mathrm{mol} / \mathrm{l}$, the plots illustrated the distinctive performance for the steel anodization in phosphoric acid [36] .In brief way, inside polarization plots, the current raised among potential increasing pending a greatest was attained, analogous to a compressed oxide layer formation on the steel surface. This was characteristically the step abruptly before or when the ultimate potential was accomplished. Subsequently a quick current molder was watched inside the current fleeting. When a lowest in current density was accomplished (characteristically behind a little minutes from the start), diminutive holes began to shape arbitrarily in the oxide layer.

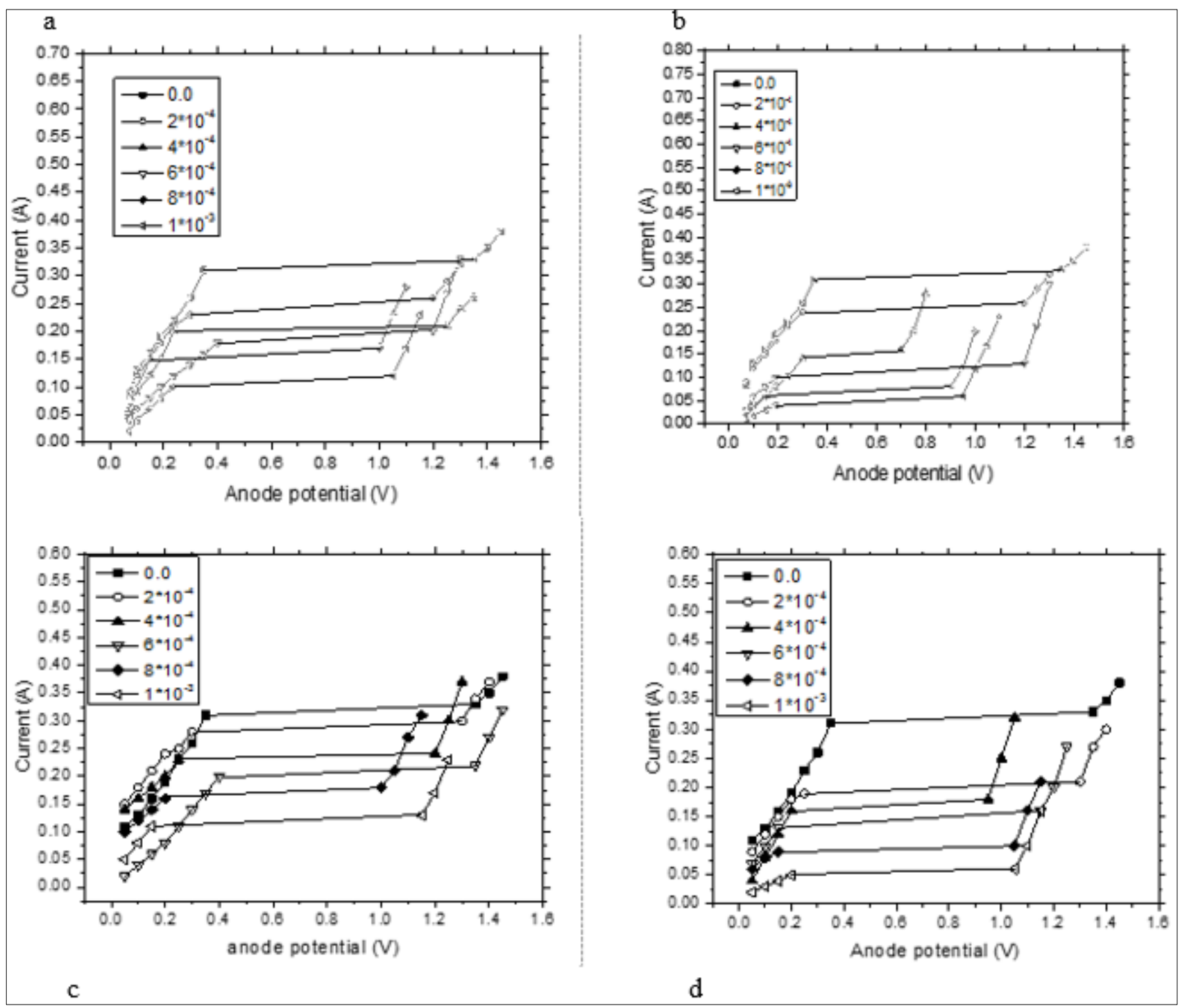

Figure 4. Polarization plots s for of vertical c-steel plates in $8 \mathrm{MH}_{3} \mathrm{PO}_{4}$ solution containing different concentrations of a) isononyl phthalate, b) n-oleyl 1.3di aminopropane,

c) sod.laurylsulphate, d) benzalkoniumcholrideat $20^{\circ} \mathrm{C}$

Owing to a superior active region the current raised over until a maximum number of apertures was expanded, equivalent to a second greatest in current density. Consequently, the holes grew in length and 
the current density reduced gradually towards a steady- state value. little dissimilarities in the performance of the substrates, i.e. in the time needed to reach the first maximum, can be explained by differences in the surface roughness [37].

It is observable that, in the organic- free solution, the current amplifies linearly at first, then tend to demonstrate limiting current plateau with raising in the anodic potential. Organic particles addition to the electrolyte solution reduces the anodic polarization and diminishes the limiting current density value. The monitored modifications in the anodic polarization in the existence of organic additive recommend that, additives may be acting as an inhibitors, that is corroborated by the surveillance that at any specified over potential, the current density for steel electro polishing from solution include organic additive is lesser than that found for the analogous organic particles - free solution.

\section{Effect of surfactant on limiting current}

Electro-polishing mechanistic study have exposed that electro polishing reaction is managed by diffusion that occur on the limiting current, the limiting current is accomplished most possibly when the diffusion film develop into saturated with $\mathrm{Fe}^{+2}$ ions [38].

Consequently the limiting current value that established the polishing rate depends on $\mathrm{Fe}^{+2}$ ions mass transfer rate from the diffusion film to the solution bulk [39]. The steel polishing rate in presence of $8 \mathrm{M}$ phosphoric acid and surfactants in electro polishing process was investigated by determining the limiting current amount that signifies electro polishing rate. This rate reduces by raising surfactants concentration which lead to solution viscosity increase

The data on Table (3) shows the addition of different surface active agents (SAS) concentrations with range from $\left(1 \times 10^{-4}\right.$ to $\left.1 \times 10^{-3}\right)$ to $8 \mathrm{M}$ phosphoric acid which decreases the rate of limiting current of steel dissolution depending on the dielectric constant mixtures and thermodynamic parameters given [40].

This decrease was pointed to SAS presence particles deposited on the steel electrode surface, that proceeds as a protective film and diminishes the $\mathrm{H}_{3} \mathrm{PO}_{4}$ and steel surface interaction.

From (Table 3), it is also obvious that the retardation amplifies with concentration enlargement that indicates that organic additives may be ranked as a dissolution inhibitor in $8 \mathrm{MH}_{3} \mathrm{PO}_{4}$ [41].

The steel anodic polarization performance is so responsive to little concentrations of the studied surfactants. The limiting current decrease with the studied SAS addition is dependable with a salt-film mechanism. When the surfactants were added, it is possible that adsorption occurred on and near to the anode helped to manage ion diffusion process in three means that is:

(i)Occupation of hollows and depressions in the metal surface.

(ii)The rate of electro-polishing over valleys is higher than that of cavities. That's why surface

leveling takes occurred due to the crevices passivation is more stable and it retards etching.

(iii) Water molecules surrounding the anode become replaced. This replacement changes the medium dielectric constant and decreases the water molecules number that solvate cations, therefore decreases the cations diffusion rate apart from the anode surface [42].

The inhibition percentage was estimated via the next equation:

$$
\text { \%Inhibition }=\left[\left(\mathrm{I}_{\mathrm{b}}-\mathrm{I}_{\mathrm{SAS}}\right) / \mathrm{I}_{\mathrm{b}}\right] \times 100
$$

where the limiting current in surfactant - free solution $\left(\mathrm{I}_{\mathrm{b}}\right)$ while the limiting current in surfactant containing solution called (ISAS). The percentage inhibition efficiencies obtained from equation (6) listed in Table (3). It is obvious that the \% Inhibition amplifies with raising the inhibitor concentrations.

The order of inhibition according to limiting current results and the percentage inhibition efficiencies (Table 3) is:

N-oleil1,3diaminopropane $>$ Benzalkonuim chloride $>$ Sodium lauryl sulphate $>$ Di- isononyl phthalate. 
This results comes with agreement with the data obtained from the surface active properties. The values of $\pi \mathrm{cmc}$ indicate that $\mathrm{N}$-oleyl 1.3 diamino propane has the most effectiveness among the four surfactants due to the large decrease in surface tension which takes place at the CMC of N-oleyl 1.3diamino propane that's why it has the largest inhibition efficiency on dissolution process followed by Benzalkounuim chloride, Soduim lauryl sulphate and Di-Isononyl phthalate respectively.

Table 3. limiting current (A)and \% inhibition values for the four studied surfactants at different concentration and temperature

\begin{tabular}{|c|c|c|c|c|c|c|c|c|c|}
\hline Organic compound & Conc(mol/L) & $20^{0} \mathrm{C}$ & & $30^{\circ} \mathrm{C}$ & & $40^{\circ} \mathrm{C}$ & & $50^{0} \mathrm{C}$ & \\
\hline \multirow{11}{*}{ DiIsononylPhthalate } & Blank & 0.31 & $\%$ IE & 0.4 & $\% \mathrm{IE}$ & 0.45 & $\% \mathrm{IE}$ & 0.48 & $\%$ IE \\
\hline & $1 \mathrm{E}-04$ & 0.3 & 3.23 & 0.39 & 2.50 & 0.44 & 2.22 & 0.51 & 1.92 \\
\hline & $2 \mathrm{E}-04$ & 0.28 & 9.68 & 0.37 & 7.50 & 0.42 & 6.67 & 0.5 & 3.85 \\
\hline & $3 \mathrm{E}-04$ & 0.26 & 16.13 & 0.35 & 12.50 & 0.42 & 6.67 & 0.49 & 5.77 \\
\hline & 4E-04 & 0.23 & 25.81 & 0.32 & 20.00 & 0.38 & 15.56 & 0.46 & 11.54 \\
\hline & $5 \mathrm{E}-04$ & 0.22 & 29.03 & 0.29 & 27.50 & 0.35 & 22.22 & 0.43 & 17.31 \\
\hline & $6 \mathrm{E}-04$ & 0.2 & 35.48 & 0.28 & 30.00 & 0.33 & 26.67 & 0.4 & 23.08 \\
\hline & $7 \mathrm{E}-04$ & 0.19 & 38.71 & 0.27 & 32.50 & 0.32 & 28.89 & 0.38 & 26.92 \\
\hline & $8 \mathrm{E}-04$ & 0.16 & 48.39 & 0.24 & 40.00 & 0.28 & 37.78 & 0.36 & 30.77 \\
\hline & 9E-04 & 0.14 & 54.84 & 0.23 & 42.50 & 0.27 & 40.00 & 0.34 & 34.62 \\
\hline & $1 \mathrm{E}-03$ & 0.11 & 64.52 & 0.22 & 45.00 & 0.25 & 44.44 & 0.32 & 38.46 \\
\hline \multirow{10}{*}{$\begin{array}{l}\text { N-oleyl 1.3diamino } \\
\text { propane }\end{array}$} & $1 \mathrm{E}-04$ & 0.22 & 29.03 & 0.34 & 15 & 0.42 & 6.67 & 0.49 & 5.77 \\
\hline & $2 \mathrm{E}-04$ & 0.19 & 38.71 & 0.31 & 22.5 & 0.4 & 11.11 & 0.48 & 7.69 \\
\hline & $3 \mathrm{E}-04$ & 0.18 & 41.94 & 0.3 & 25 & 0.37 & 17.78 & 0.46 & 11.54 \\
\hline & $4 \mathrm{E}-04$ & 0.14 & 54.84 & 0.28 & 30 & 0.35 & 22.22 & 0.43 & 17.31 \\
\hline & $5 \mathrm{E}-04$ & 0.12 & 61.29 & 0.23 & 42.5 & 0.31 & 31.11 & 0.4 & 23.08 \\
\hline & $6 \mathrm{E}-04$ & 0.1 & 67.74 & 0.22 & 45 & 0.28 & 37.78 & 0.37 & 28.85 \\
\hline & 7E-04 & 0.08 & 74.19 & 0.19 & 52.5 & 0.26 & 42.22 & 0.34 & 34.62 \\
\hline & $8 \mathrm{E}-04$ & 0.06 & 80.65 & 0.17 & 57.5 & 0.23 & 48.89 & 0.32 & 38.46 \\
\hline & 9E-04 & 0.05 & 83.87 & 0.16 & 60 & 0.21 & 53.33 & 0.3 & 42.31 \\
\hline & $1 \mathrm{E}-03$ & 0.04 & 87.10 & 0.14 & 65 & 0.18 & 60.00 & 0.28 & 46.15 \\
\hline \multirow[t]{10}{*}{ Sodium lauryl sulphate } & $1 \mathrm{E}-04$ & 0.27 & 12.90 & 0.36 & 10 & 0.44 & 2.22 & 0.51 & 1.92 \\
\hline & $2 \mathrm{E}-04$ & 0.23 & 25.81 & 0.33 & 17.5 & 0.41 & 8.89 & 0.5 & 3.85 \\
\hline & $3 \mathrm{E}-04$ & 0.21 & 32.26 & 0.32 & 20 & 0.39 & 13.33 & 0.48 & 7.69 \\
\hline & $4 \mathrm{E}-04$ & 0.2 & 35.48 & 0.31 & 22.5 & 0.37 & 17.78 & 0.45 & 13.46 \\
\hline & $5 \mathrm{E}-04$ & 0.19 & 38.71 & 0.28 & 30 & 0.33 & 26.67 & 0.42 & 19.23 \\
\hline & $6 \mathrm{E}-04$ & 0.18 & 41.94 & 0.27 & 32.5 & 0.31 & 31.11 & 0.39 & 25.00 \\
\hline & 7E-04 & 0.17 & 45.16 & 0.26 & 35 & 0.3 & 33.33 & 0.37 & 28.85 \\
\hline & $8 \mathrm{E}-04$ & 0.15 & 51.61 & 0.23 & 42.5 & 0.27 & 40.00 & 0.35 & 32.69 \\
\hline & 9E-04 & 0.13 & 58.06 & 0.22 & 45 & 0.26 & 42.22 & 0.33 & 36.54 \\
\hline & $1 \mathrm{E}-03$ & 0.1 & 67.74 & 0.21 & 47.5 & 0.24 & 46.67 & 0.31 & 40.38 \\
\hline \multirow[t]{10}{*}{ Benzalkonium chloride } & $1 \mathrm{E}-04$ & 0.31 & 16.13 & 0.4 & 12.5 & 0.45 & 4.44 & 0.52 & 3.85 \\
\hline & $2 \mathrm{E}-04$ & 0.26 & 35.48 & 0.35 & 20 & 0.43 & 11.11 & 0.5 & 5.77 \\
\hline & $3 \mathrm{E}-04$ & 0.2 & 45.16 & 0.32 & 22.5 & 0.4 & 15.56 & 0.49 & 9.62 \\
\hline & $4 \mathrm{E}-04$ & 0.17 & 48.39 & 0.31 & 25 & 0.38 & 20.00 & 0.47 & 15.38 \\
\hline & $5 \mathrm{E}-04$ & 0.16 & 54.84 & 0.3 & 40 & 0.36 & 31.11 & 0.44 & 21.15 \\
\hline & $6 \mathrm{E}-04$ & 0.14 & 58.06 & 0.24 & 42.5 & 0.31 & 35.56 & 0.41 & 26.92 \\
\hline & $7 \mathrm{E}-04$ & 0.13 & 64.52 & 0.23 & 50 & 0.29 & 40.00 & 0.38 & 30.77 \\
\hline & $8 \mathrm{E}-04$ & 0.11 & 70.97 & 0.2 & 55 & 0.27 & 44.44 & 0.36 & 34.62 \\
\hline & 9E-04 & 0.09 & 77.42 & 0.18 & 57.5 & 0.25 & 48.89 & 0.34 & 40.38 \\
\hline & $1 \mathrm{E}-03$ & 0.07 & 83.87 & 0.17 & 62.5 & 0.23 & 55.56 & 0.31 & 44.23 \\
\hline
\end{tabular}

\subsection{Effect of surfactants structure in electro polishing process}

Among a diversity of anodic inhibitors procedures, the operation of organic molecules has been classified as an proficient and sensible scheme as they may guard metal substrate from being rotten in aqueous solution through adsorbing themselves on the metal surface and shaping a protecting layer. On the other hand, most usually used organic inhibitors are not only costly but also precarious to ecosystem and atmosphere [43], that has punctuated the explore for economical, willingly obtainable and green inhibitors. Organic inhibitors normally have heteroatoms, such as $\mathrm{O}, \mathrm{N}, \mathrm{S}, \mathrm{P}$ atoms. The hetero atoms have superior basicity and electron density and may operate as active centers for the adsorption process 
on the metal surface [44]. Surfactants that contain $\mathrm{O}$ and $\mathrm{N}$ heteroatoms have been used as the layer formers to create barricade layers on the metal and metal oxides surfaces, with the principle of preserving their original luster [45] Consistent with the related studies, the surfactants adsorb onto the metal surface via the specific hydrophilic functional groups adsorption and the long alkyl chains interact together via van der Waals interactions to form the established monolayer coat [45]. So the retardation surfactants efficiency is influenced not only by the metal nature and metal surface charge to be sheltered, but also by the inhibitors molecular structure.

$\mathrm{N}$-oleil 1.3 diamino propane is a nonionic surfactant composed of a fairly polar hydrophilic part of $\left(\mathrm{NH}_{2}-\mathrm{CH}_{2}-\mathrm{CH}_{2}-\mathrm{CH}_{2}-\mathrm{NH}-\mathrm{CH}_{2}\right)$ and a hydrophobic part from $\left(\mathrm{C}_{17} \mathrm{H}_{27}\right)$. The decrease occurred on dissolution rate of steel in $8 \mathrm{M} \mathrm{H}_{3} \mathrm{PO}_{4}$ by $\mathrm{N}$-oleil 1.3 diamino propane can be attributed to two factors; molecular adsorption and the CMC barrier conditions. Under CMC, $\mathrm{N}$-oleil 1.3 diamino propane is exhibit the monolayer level on the surface of the electrode, and above the CMC adsorption of N-oleil 1.3 diamino propane may forma multiple layers of physically adsorbed molecules. By increasing surfactant concentration after the CMC concentration, a gradual formation of multi layers that lead to reduction in the rate of electro polishing more than that estimated from the monolayer coverage resulted from concentrations lower than that of the CMC. In other meaning; the increasing in thickness of multi layers and thus increasing surface barrier layer viscosity are the reason why additional increase in dissolution inhibition above CMC takes place [45], while for Di-isononyl phthalate which is also a nonionic surfactant contains four polar oxygen atoms surrounded by benzene ring and hydrophobic alkyl chain, from Table 3 it was found that by increasing surfactant concentration the limiting current decreases thus the dissolution rate decrease and from Table 3 it was found that $\%$ IE enlarges also via raising surfactant concentration that's may be attributed to the Vander Waals forces interaction between the partially negatively charged oxygen atoms and the positively charged $\mathrm{Fe}^{+2}$ ions resulting from dissolution of the anode and the physical adsorption on the surface of electrode forming mono layer at small negatively charged oxygen atoms and the positively charged $\mathrm{Fe}^{+2}$ ions resulting from dissolution of the anode and the physical adsorption on the surface of electrode forming mono layer at small concentrations and hemi micelles at concentration exceeds the CMC. From Table 3 it was found that the efficiency of inhibition for N-oleil 1,3 di amino propane is larger than Di isononyl phthalate and that may be attributed to the loose physical interaction of the Di-isononyl phthalate at high concentrations than that of N-oleil 1,3 di amino propane due to the steric hindrance of the two alkyl groups and the benzene ring and the poor electrostatic interaction of the oxygen atoms due to being surrounded by the hydrophobic parts of the surfactants.

For Sodium lauryl sulphate which has $\left(\mathrm{C}_{12} \mathrm{H}_{25} \mathrm{SO}_{4}{ }^{-1}\right)$, it was found that, the anodic dissolution rate diminishes with increasing concentrations of surfactant. It was found that, the dissolution inhibition action of Sodium luaryl sulphate in $8 \mathrm{M} \mathrm{H}_{3} \mathrm{PO}_{4}$ consequences from physical (electrostatic interaction) adsorption of the two opposite charges of the steel ions from dissolution and charge on Sodium lauryl sulphate forming a barricade on steel surface. At low concentration of Sodium lauryl sulphate, the negative charge possessed by sulphate group adsorbed on the positive charges of $\mathrm{Fe}^{+2}$ on the electrode. By increasing concentration of Sodium lauryl sulphate, the barrier thickness consists of Sodium lauryl sulphate increases forming a hemimicelles as a result of the interaction between the oxygen atoms via Vander Waals forces. The barricade turn int more strong by adsorption of the extremely negatively charged Sodium lauryl sulphate micelle (when the surfactant concentration exceeds the CMC, the micelles number enlarges but the free surfactant molecules remains constant at the CMC). So more decrease in limiting current and elevated IE\% will happen after CMC of sodium lauryl sulphate [46].In addition Sodium lauryl sulphate is used as wetting agents also the sulphur bound directly to an atom of carbon, may be successfully used in brightness of the anode.

For Benzalkonium chloride, it's clear that the limiting current of steel dissolution in $8 \mathrm{M} \mathrm{H}_{3} \mathrm{PO}_{4}$ in attendance of surfactant reduces and IE\% raises by increasing the surfactant concentration [44]. At high concentration the inhibitory effect of Benzalkonium chloride is so obvious as it has a elevated retardation efficiency that may be featured to the fact that addition of Benzalkonium chloride will increase $\mathrm{Cl}^{-}$anion 
present in $\mathrm{H}_{3} \mathrm{PO}_{4}$ acid solution which will be adsorbed at the electrode/solution boundary via electrostatic interaction and increase the number of negative charges oriented towards the solution stage and insures additional adsorption of positively charged Benzalkonium cation. Thus the Benzalkonium chloride will be electrostatically adsorbed on the electrode surface enclosed with mainly adsorbed chloride ions [45]. Benzalkounuim chloride as a cationic surfactant added a roughness significant to the steel surface as well to the presence of an aromatic group leads to the brightening view.

\section{Temperature effect and activation parameters}

Temperature can affect the electrochemical behavior of a metal in the polishing environmental conditions. The temperature effect on the retardation accomplishment of the inhibitor was established at different concentrations and at diverse temperatures $\left(20-50^{\circ} \mathrm{C}\right)$. The tabulated results (Table 3$)$ expose that as the inhibitor concentration amplifies, the dissolution rate enlarges with raising temperature both in the surfactant-free solution and surfactant containing solution, while from (Table 3) \% IE reduces with temperature augment. This enhancing could be elucidated on the basis that increasing temperature improves the $\mathrm{PO}_{4}{ }^{-3}$ ions transfer rate and the conductivity will increase. Also the temperature raising will reduce solution viscosity with a consequential augment in $\mathrm{Fe}^{2+}$ ion diffusivity that resulting in dissolution rate raising [47]. The reduce in IE\% is due to surfactants molecules desorption on the Fe surface via raising temperature. The diminish in inhibition efficiency via raising temperature is evocative of physical adsorption of the investigated surfactants on the steel surface [10].

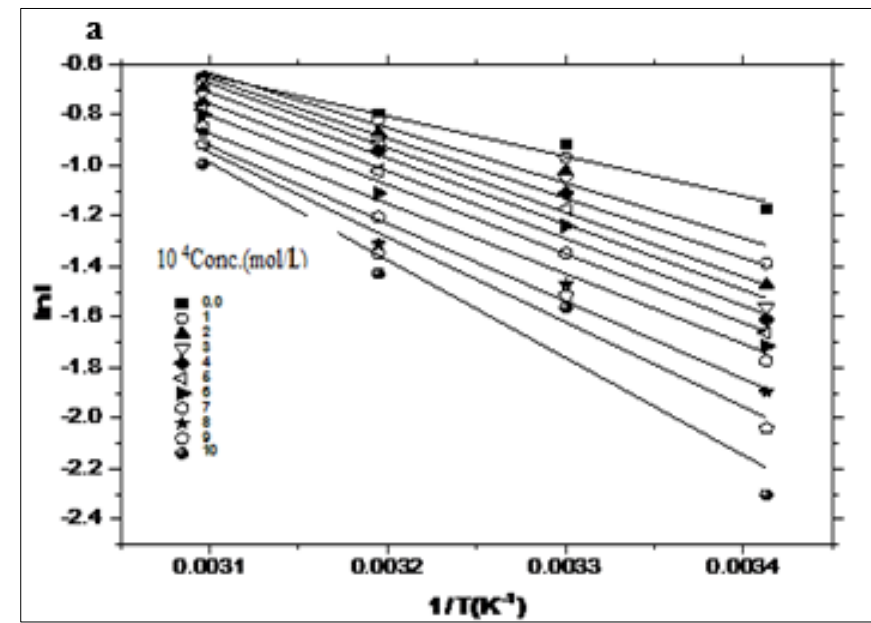

a

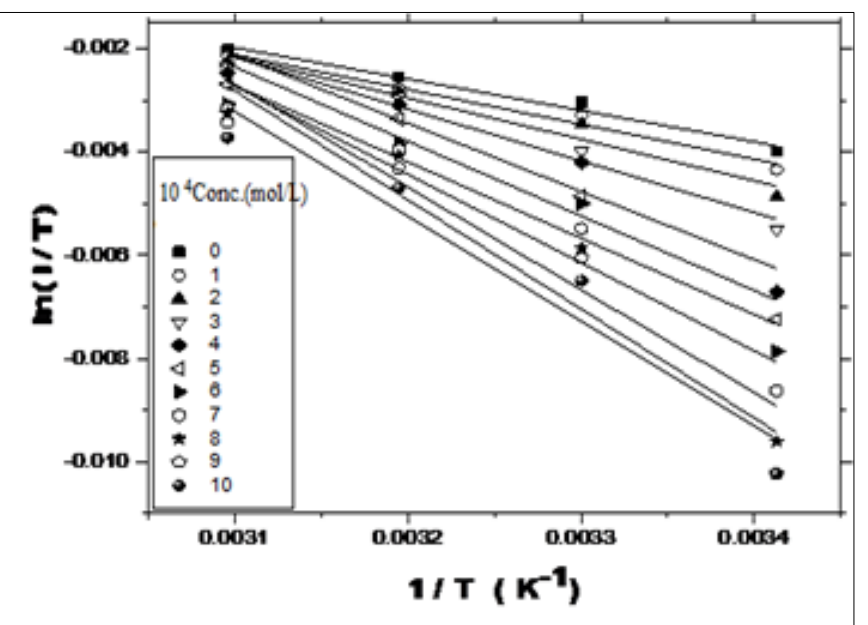

b

Figure 5. (a) Arrhenius plot, (b)Transition state plot of the recorded for copper dissolution process in $8 \mathrm{M} \mathrm{H}_{3} \mathrm{PO}_{4}$ solution containing several concentration of Di isononyl phthalate

Electro polishing process can be regarded as an Arrhenius-type procedure Eq. 7 and transition-state equation 8; the activation parameters for the investigated system were estimated from Arrhenius equation with the aid of the values of $\mathrm{I}_{1}$ gained at several temperature.

The activation energy Ea calculated from Arrhenius equation:

Transition-state equation:

$$
\ln \mathrm{I}=-\mathrm{Ea} / \mathrm{RT}+\ln \mathrm{A}
$$

$$
\mathrm{I}_{\mathrm{L}}=(\mathrm{RT} / \mathrm{Nh}) \exp \left(\Delta \mathrm{S}^{*} / \mathrm{R}\right) \exp \left(-\Delta \mathrm{H}^{*} / \mathrm{RT}\right)
$$

where:

A: pre-exponential factor, that imitates the additives adsorption capacity on metal surface

R: molar gas constant, T: absolute temperature, N: Avogadro's number and H: Planck's constant 
The enthalpy of activation $\Delta \mathrm{H}^{*}$, entropy of activation $\Delta \mathrm{S}^{*}$, and free energy of activation $\Delta \mathrm{G}^{*}$ values can also be calculated via utilizing the following equations were their values mentioned in Table (4):

$$
\begin{gathered}
\Delta \mathrm{H}=\mathrm{Ea}-\mathrm{RT} \\
\Delta \mathrm{S} / \mathrm{R}=\ln \mathrm{A}-\ln (\mathrm{kTe} / \mathrm{h}) \\
\Delta \mathrm{G}^{*}=\Delta \mathrm{H}^{*}-\mathrm{T} \Delta \mathrm{S}
\end{gathered}
$$

where:

$\mathrm{k}$ : is Boltzmann's constant, e: $=2.7183$, h: is Plank's constant, A:is Arrhenius constant, T:is absolute temperature, ${ }^{\circ} \mathrm{K}$ and $\mathrm{R}:$ is the universal gas constant $=8.314 \mathrm{Jmol}^{-1} \mathrm{~K}^{-1}$.

From Arrhenius equation the plot of $\ln \mathrm{I}_{\mathrm{L}}$ against $1 / \mathrm{T}$ provide a straight line as shown in fig $(5 \mathrm{a})$ with slope proportional to $\mathrm{Ea} / \mathrm{R}$ and intercept equal to $\ln \mathrm{A}$ and applying to transition state equation a relation between $\mathrm{Ln}\left(\mathrm{I}_{\mathrm{L}} / \mathrm{T}\right)$ versus $1 / \mathrm{T}$ shows linear curves as mentioned in Figure $(5 \mathrm{~b})$. with slope of $-\Delta \mathrm{H}^{*} / \mathrm{R}$ and intercept $\ln (\mathrm{R} / \mathrm{Nh})+\Delta \mathrm{S}^{*} / \mathrm{R}$ proved the high degrees of linearity that obtained reflecting that the adsorption of this inhibitor properly fitted the Transition state model. Arrhenius and Transition state plots were configured for steel in $8 \mathrm{M} \mathrm{H}_{3} \mathrm{PO}_{4}$ solutions with different concentrations of the four surfactants under study different temperature $\left(20-50^{\circ} \mathrm{C}\right)$. Figure $4 \mathrm{a}$ and $4 \mathrm{~b}$ shows the Arrhenius and Transition state plots, originate from electro polishing measurements of steel in $8 \mathrm{M} \mathrm{H}_{3} \mathrm{PO}_{4}$ solutions at different concentrations of the four studied surfactants ranging from $1 \times 10^{-4}$ to $1 \times 10^{-3}$. The thermodynamic activation parameters were originated from these curves and tabulated in Table (4) for each surfactant concentration. From the data obtained from Table (4) it was found that In free surfactants solution, the results fit well with a instantly line with an activation energy equals to (13.19 k.J.mol-1) which is lower than the values gained from surfactants in $8 \mathrm{M} \mathrm{H}_{3} \mathrm{PO}_{4}$ indicating that surfactants can be classified as anodic dissolution inhibitor, this can be ascribed to the chemical interaction nature among additive molecules and the steel surface. These consequences will be established via the pre-exponential feature in the Arrhenius equation where the (A) values in case of adding surfactant are larger than that of surfactant free solution, this may be ascribed to the fact that the surfactant molecules are adsorbed on the mainly active adsorption sites (possessing the highest energy) and the dissolution procedure occur. The increase of the activation energy by increasing SAS concentration might be connected to the increasing in the electrical double layer thickness as a result enhancement of the activation energy of the dissolution process takes place $[48,49]$.

It is showed that the of $\Delta \mathrm{H}^{\#}$ values after further raising of the surfactants concentration augments, This can be ascribed to the fact that the raise in surfactants concentration increases energy barrier value of the anodic dissolution reaction to a value that directly proportional to the concentration of the added surfactant indicating the endothermic nature of the electro polishing process [11]. It was observed that the values of $\Delta \mathrm{S}^{\#}$ highly negative whatever the surfactant was added or not which illustrate that the activated complex at the step before the rate determining step favors the organization bath rather than dissociation step in other meaning, the disorder decreases continuing from reactants to the activated complex. Thus a higher order shows on transformation from reactants to the activated complex [45]. $\Delta \mathrm{G}^{\#}$ values shows increase on increasing concentration of organic surfactants, $\Delta \mathrm{G}$ values after inhibition was more positive than that for the blank illustrating the weak dependence of $\left(\Delta G^{\#}\right)$ on the organic additives composition. In all cases $\left(\Delta \mathrm{H}^{\#}\right)$ and $\left(\Delta \mathrm{S}^{\#}\right)$ compensate each other to produce that change in $\left(\Delta \mathrm{G}^{\#}\right)$.

The pre-exponential factor in the Arrhenius equation (A), for heterogeneous reaction is accompanied with the number of active sites at surface of the electrode. The surfactant molecules that area adsorbed at the surface of the electrode block apart from the active sites that's with lower activation energy value. And due to the fact that these active sites possess different values of energies, we will have two probabilities; 1) if the activation energy after addition of the surfactant is higher than that of free acid such as the case of the four studied surfactant of this study, here we notice that A in case of surfactant addition is superior than that of free acid. The surfactants molecules are adsorbed on the greatest active adsorption sites (thus having the lowest energy) and the dissolution process occur on the active sites of elevated energy. If the activation energy after addition of the surfactant is lower than that of free acid, 
the values of (A)on addition of the surfactant is lower than that of free acid. Thus a decrease in number of active sites that are remaining uncovered which participate in the anodic dissolution process [42].

\section{Scanning electron microscope}

SEM was made to investigate the steel pieces surface morphology. Specimens micrographs before and after electro-polishing in acid -surfactant free solution and acid containing several concentrations of investigated surfactants are shown in Figure 6.

The steel surface morphology which were dissolved in $8 \mathrm{M} \mathrm{H}_{3} \mathrm{PO}_{4}$ at $20^{\circ} \mathrm{C}$ which after examining it a bad, un even and damaged surface is seen also large deep pits and number of white spots are clearly appeared for raw sample Figure (6a)

After electro polishing of the blank steel sheet the surface texture were enhanced to some extent fig. (6b) after addition of low concentration from Di isononyl phthalate Figure (6c) it is showed that , there is enhancement in surface texture to small extent grain boundaries are the most shape represented on the sample as deep cavities were also found but after the addition of high concentration from Di isononyl phthalate Figure (6d) grain boundaries were disappeared and surface appears more uniform which may be ascribed to surfactants adsorption on steel surface and improvement of the surface texture takes place, the same appearance took place for Sodium lauryl sulphate as at low concentration (Figure $6 \mathrm{~g}$ ) is more damaged from the high concentration (Figure 6h).

Table 4. Values of thermodynamic parameters for dissolution of Steel in $8 \mathrm{M} \mathrm{H}_{3} \mathrm{PO}_{4}$

\begin{tabular}{|c|c|c|c|c|c|c|}
\hline \multirow{2}{*}{$\begin{array}{c}10{ }^{4} \text { Conc. } \\
(\mathrm{mol} / \mathrm{l})\end{array}$} & \multicolumn{6}{|l|}{ SAS } \\
\hline & \multirow{13}{*}{ 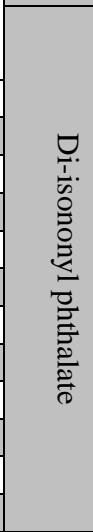 } & $\begin{array}{c}\mathrm{Ea} \\
\mathrm{kj} \cdot \mathrm{mol}^{-1}\end{array}$ & $10^{3} \mathrm{~A}$ & $\begin{array}{c}\Delta \mathrm{H}^{\#} \\
\text { kj. } \mathrm{mol}^{-1}\end{array}$ & $\begin{array}{c}-\Delta \mathrm{S}^{\#} \\
\mathrm{~J} \cdot \mathrm{mol}^{-1} \cdot \mathrm{K}^{-1}\end{array}$ & $\begin{array}{c}\Delta \mathrm{G}^{\#} \\
\mathrm{kj} \cdot \mathrm{mol}^{-1}\end{array}$ \\
\hline 0.0 & & 13.19 & 4.27 & 21.76 & 217.6 & 75.62 \\
\hline & & & & & & \\
\hline 1.0 & & 18.12 & 6.12 & 15.69 & 202.31 & 75.97 \\
\hline 2.0 & & 19.69 & 6.68 & 17.21 & 197.66 & 76.14 \\
\hline 3.0 & & 21.21 & 7.23 & 18.73 & 193.09 & 76.30 \\
\hline 4.0 & & 21.65 & 7.35 & 19.17 & 192.04 & 76.43 \\
\hline 5.0 & & 22.18 & 7.51 & 19.70 & 190.7 & 76.58 \\
\hline 6.0 & & 22.74 & 7.67 & 20.26 & 189.43 & 76.74 \\
\hline 7.0 & & 23.07 & 7.72 & 20.59 & 188.98 & 76.94 \\
\hline 8.0 & & 25.56 & 8.607 & 23.09 & 181.66 & 77.25 \\
\hline 9.0 & & 27.90 & 9.45 & 25.42 & 174.63 & 77.49 \\
\hline 10.0 & & 29.62 & 10.97 & 29.62 & 161.95 & 77.91 \\
\hline & & & & & & \\
\hline$\frac{1.0}{2.0}$ & 7 & $\frac{14.74}{15.2}$ & $\begin{array}{c}4.80 \\
5.9\end{array}$ & $\frac{12.26}{15.24}$ & $\begin{array}{l}213.27 \\
152.47\end{array}$ & $\begin{array}{l}75.85 \\
76.11\end{array}$ \\
\hline 3.0 & 0 & 22.56 & 7.6 & 20.08 & 189.22 & 76.50 \\
\hline 4.0 & $\stackrel{\mathbb{Q}}{\longleftarrow}$ & 30.24 & 10.56 & 27.76 & 165.35 & 77.06 \\
\hline 5.0 & 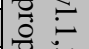 & 33.12 & 11.56 & 30.64 & 157.03 & 77.46 \\
\hline 6.0 & 岂 & 33.63 & 11.64 & 31.15 & 156.44 & 77.79 \\
\hline 7.0 & $\begin{aligned} & \sigma= \\
& \cong\end{aligned}$ & 39.17 & 13.7 & 36.69 & 139.32 & 78.23 \\
\hline 8.0 & 疋. & 45.99 & 16.24 & 43.51 & 118.14 & 78.73 \\
\hline 9.0 & 0 & 46.5 & 17.27 & 46.37 & 109.61 & 79.05 \\
\hline 10.0 & & 51.99 & 18.35 & 49.51 & 100.61 & 79.51 \\
\hline & & & & & & \\
\hline 1.0 & & 13.53 & 4.38 & 11.05 & 216.79 & 75.69 \\
\hline 2.0 & $\tilde{0}$ & 14.27 & 4.61 & 11.79 & 214.83 & 75.84 \\
\hline 3.0 & : & 15.31 & 4.97 & 12.82 & 211.88 & 76.003 \\
\hline 4.0 & $\Xi$ & 15.93 & 5.15 & 13.45 & 210.32 & 76.16 \\
\hline 5.0 & $\bar{\cong}$ & 15.85 & 5.05 & 13.37 & 211.19 & 76.34 \\
\hline 6.0 & $\underline{\leq}$ & 16.96 & 5.42 & 14.48 & 208.13 & 76.54 \\
\hline 7.0 & $\stackrel{\mathscr{E}}{\Xi}$ & 17.71 & 5.64 & 15.23 & 206.28 & 76.73 \\
\hline 8.0 & $\overline{\underline{\sigma}}$ & 20.33 & 6.54 & 17.85 & 198.83 & 77.14 \\
\hline 9.0 & $\tilde{\tilde{\sigma}}$ & 21.54 & 6.91 & 19.06 & 195.71 & 77.42 \\
\hline 10.0 & & 25.97 & 8.52 & 23.50 & 182.32 & 77.86 \\
\hline
\end{tabular}




\begin{tabular}{|c|c|c|c|c|c|c|}
\hline & & & & & & \\
\hline 1.0 & \multirow{10}{*}{ 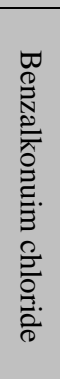 } & 19.71 & 6.71 & 17.23 & 197.40 & 76.09 \\
\hline 2.0 & & 24.05 & 8.25 & 21.75 & 184.57 & 76.60 \\
\hline 3.0 & & 25.82 & 8.88 & 23.34 & 179.38 & 76.82 \\
\hline 4.0 & & 25.01 & 8.48 & 22.52 & 182.66 & 76.99 \\
\hline 5.0 & & 26.76 & 9.03 & 24.19 & 178.06 & 77.29 \\
\hline 6.0 & & 27.71 & 9.36 & 25.23 & 175.38 & 77.52 \\
\hline 7.0 & & 29.57 & 9.99 & 27.09 & 170.13 & 77.89 \\
\hline 8.0 & & 32.54 & 11.00 & 29.97 & 161.77 & 78.20 \\
\hline 9.0 & & 36.13 & 12.25 & 33.65 & 151.31 & 78.76 \\
\hline 10.0 & & 43.26 & 14.82 & 40.78 & 129.97 & 79.54 \\
\hline
\end{tabular}

In Figure (6e) Benzalkonium chloride also at low concentration the grain boundaries and pits were clearly disappeared but at high concentration of N-oleil1.3diamino propane Figure (6f) the surface appear smooth, even and uniform

In (Figure 6i) at low concentration of N-oleil1.3diamino propane, the surface appears even to great extent but at high concentration (Figure $6 \mathrm{j}$ ) the appearance were well uniform since the grain boundaries and pits are covered via adsorption of $\mathrm{N}$-oleil1.3diamino propane particles on $\mathrm{C}$-steel surface

Finally we can conclude that Benzalkonium chloride and N-oleil1.3diamino propane achieved the highest inhibition efficiency but have positively influence on the surface texture. Since the surface appear well promising, smooth, bright and uniform especially at high concentration

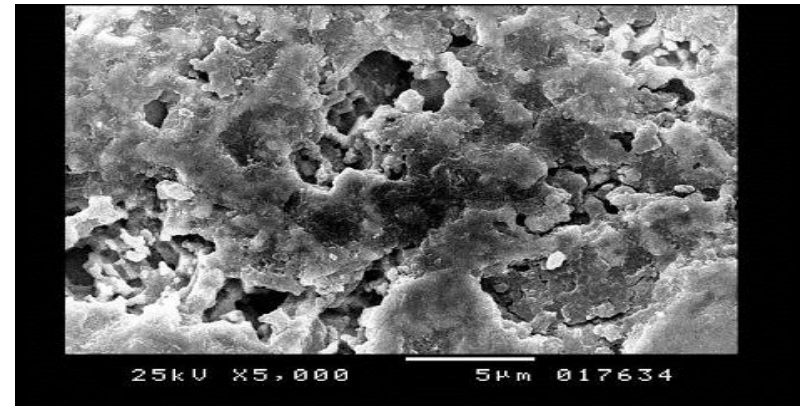

Figure 6a. Raw sample

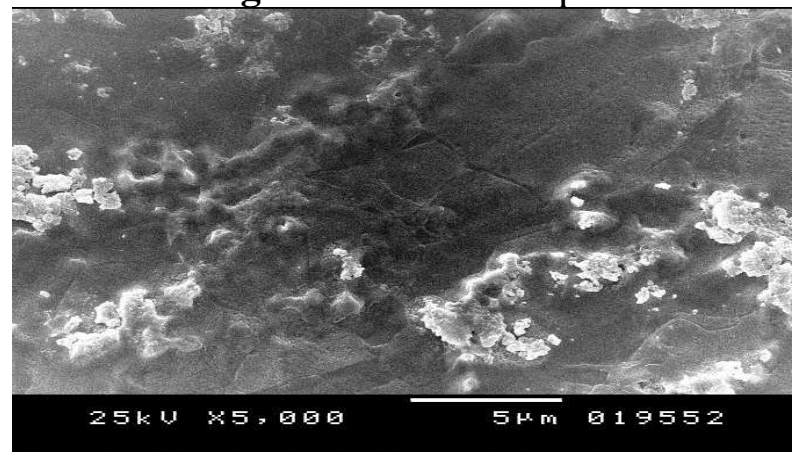

Figure 6c. At $2 \times 10^{-4} \mathrm{M}$ di-isonoyl phthalate

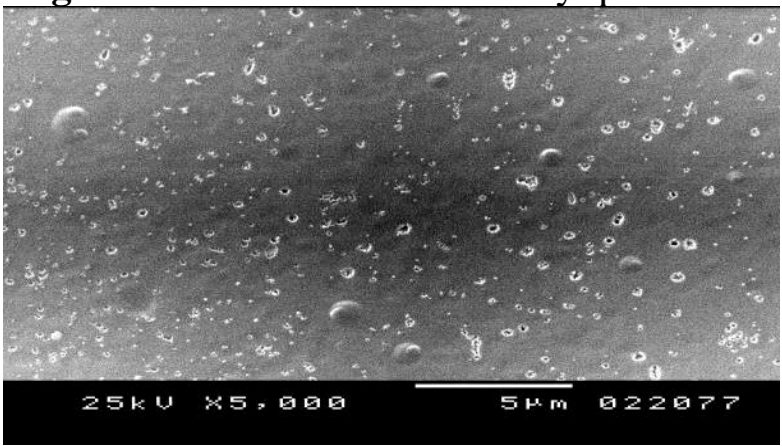

Figure 6e. At $2 \times 10^{-4} \mathrm{M}$ sodium lauryl sulphate

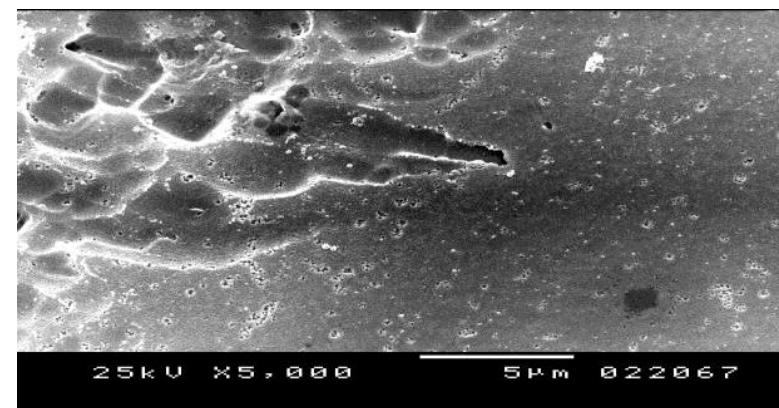

Figure 6b. Blank sample

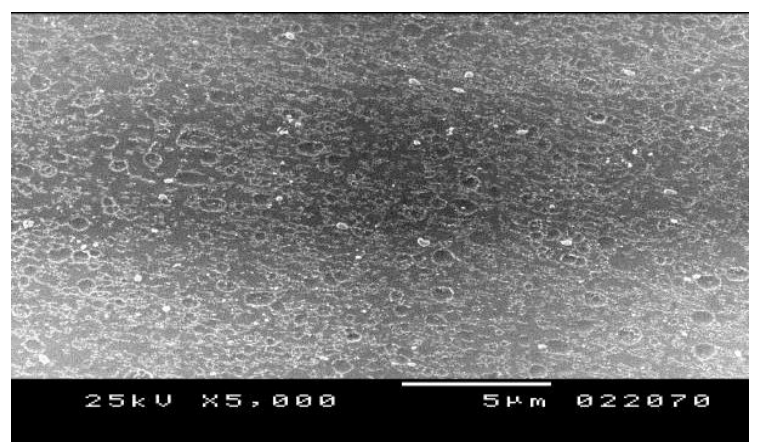

Figure 6d. At $10 \times 10^{-4} \mathrm{M}$ di-isonoyl phthalate

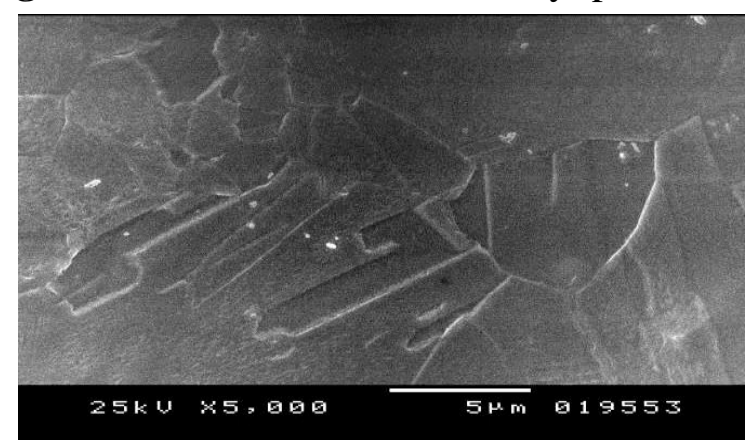

Figure 6f. At $10 \times 10^{-4} \mathrm{M}$ sodium lauryl sulphate 


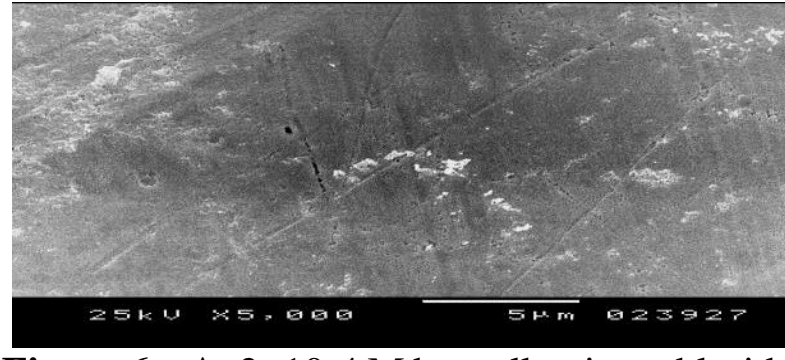

Figure 6g. At 2×10-4 M benzalkonium chloride

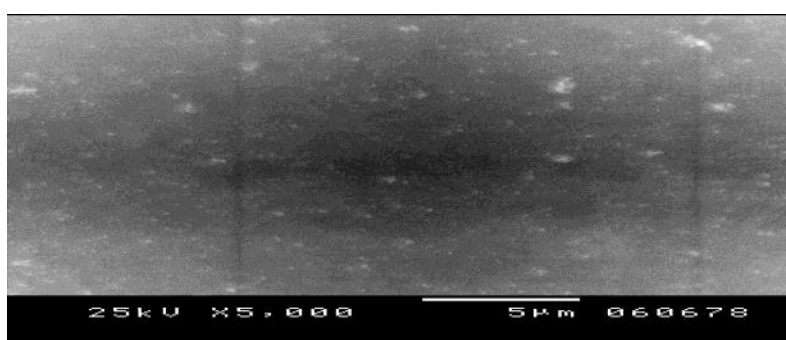

Figure 6i. At $2 \times 10^{-4} \mathrm{M}$ n-oleil1.3diamino propane

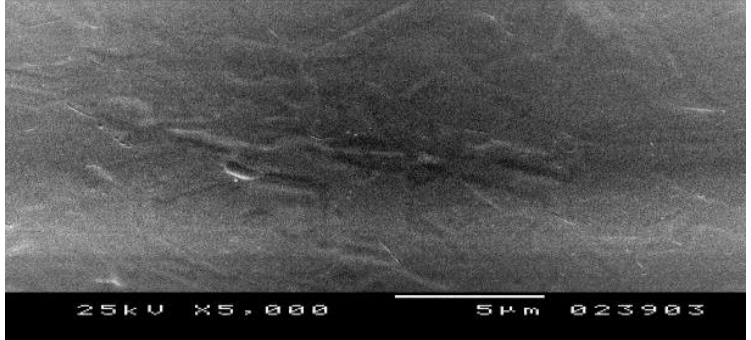

Figure $6 \mathrm{~h}$. At $10 \times 10^{-4} \mathrm{M}$ benzalkonium chloride

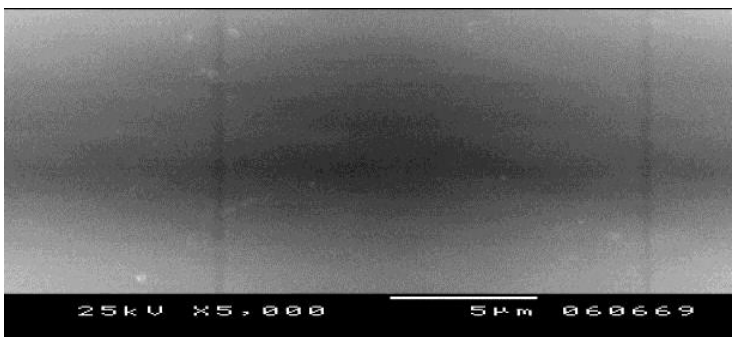

Figure 6j. At $10 \times 10^{-4} \mathrm{M}$ n-oleil1.3diamino propane

Figure 6. Scanning electron microscopes images of Steel in $8 \mathrm{M} \mathrm{H}_{3} \mathrm{PO}_{4}$ free solution and $8 \mathrm{M} \mathrm{H}_{3} \mathrm{PO}_{4}$ solution containing $2 \times 10^{-4}$ and $10 \times 10^{-4} \mathrm{~mol} / \mathrm{L}$ of surfactant at $20^{\circ} \mathrm{C}$

\section{Conclusions}

For the investigated surfactant, the $\mathrm{C}$-steel dissolution rate reduces with the raising of concentration and retardation efficiency is a SAS concentration dependant. Critical micelle concentration regard as a main factor in influential the effectiveness of SAS as corrosion retardation substance. Surfactant compounds augment the activation energy value of dissolution process and therefore reduce the C-steel dissolution rate in $\mathrm{H}_{3} \mathrm{PO}_{4}$ solution. The retardation mechanism is ascribed to the strong adsorption capability of the investigated surfactants on C-steel surface, forming a excellent protective film, that separate the surface from the destructive environment. SAS played the part of retardation, diminishing the acid etching action, and increasing the surface brightness. In the presence of the SAS, the solution appeared hopeful, and a distinctive development in the finish was observed. Improvement produced an EP by the investigated SAS was owing the surfactant adsorption on the anode surface

\section{References}

1.ABBOTT, A. P, CAPPER. G, SWAIN, B. G., WHEELER, D. A, Electro polishing of stainless steel in an ionic liquid, Trans. Inst. Met. Fin., 2005, vol. 83, p .51

2.AL-SABAGH, A.M, ABDUL-RAOUF, M.E, ABDEL-RAHEEM, R, Surface activity and light scattering investigation for some novel aromatic polyester amine surfactants Colloid Surf. A: Physicochem. Eng. Aspects. 2004, vol.251, p.167.

3. MAJEED. N. S., ALABDLY. H. A., AL ANI. H. N. A., PASCU. D., NECHIFOR. A. C., Study the Effect of Gum Arabic and Triton X-100 on Stability and Thermal Conductivity of ZnO/ethylene glycol Nanofluids, Rev. Chim., 72(1)2021, p. 18.

4.HEGAZY. M.A, EL-TABEI. A.S, AHMED. H.M, Synthesis of nonionic surfactants and their inhibitive action on carbon steel in hydrochloric acid Corros. Sci., 2012, vol. 64, p. 115.

5.IVANOV. S, RAJCIC-VUJASINOVI. M., STEVI. Z, The influence of gelatin on the corrosion behavior of cold worked copper wire in alkaline media, J. Min. Metall., 2006, vol.42B, p. 33.

6. WEI. Z, DUBY. P, SOMASUNDARAN. P, Pitting Inhibition of Stainless Steel by Surfactants: An Electrochemical and Surface Chemical Approach, J. Colloid Interface Sci., 2003, vol. 259, p. 97. 
7.HASSAN. H.H, Inhibition of mild steel corrosion in hydrochloric acid solution by triazole derivatives: Part II: Time and temperature effects and thermodynamic treatments, Electrochim. Acta., 2007, vol. 53, p. 1730.

8.QURAISHI. M.A., RAfiQUEE, M. Z. A., KHAN. S., SAXENA., N, Corrosion inhibition of aluminium in acid solutions by some imidazoline derivatives. J.Appl. Electrochem., 2007, vol.37, p. 1153.

9. ABOUZEID, F.M, Surface active properties of gelatin and their effect on the electropolishing and corrosion behavior of steel in orthophosphoric acid, Egypt. J. Pet.2016, vol.25, p.229

10. ABOUZEID, F.M., Comparison Between Electropolishing Behavior of Copper and Mild Steel in the Presence of Lactic and Mandolic Acid. Int. J. Electrochem. Sci., 2016, vol.11, p. 7269

11.TAHA. A. A, ABOUZEID. F.M, ELSADEK. M.M, HABIB. F.M ,Effect of methanolic plant extract on copper electro-polishing in Ortho-phosphoric, Arab. J. Chem.2020, vol.13, P.6006

12. ABDEL RAHMAN. H.H, SELEIM. S.M, HAFEZ. A.M., HELMY. A.A., Study of electropolishing inhibition of steel using natural products as a green inhibitor in ortho-phosphoric acid, Green Chem. Lett. Rev., 2015, vol. 8, p. 88.

13. TAHA. A.A, ABOUZEID. F.M, KANDIL. M.M, Some Drugs Effect on the Electropolishing of CSteel in $\mathrm{H}_{3} \mathrm{PO}_{4}$ Acid under Normal and Compulsory Convection Circumstances, Russ. J. Electrochem., 2020, vol. 56, p.189

14. IORDOC. M, MARIN. G, STOIANOVICI. G, PRIOTEASA. P, BALAN. C, GUTA. M, FURTUNA. R., Increasing Corrosion Resistance of Pressure Vessels at the Hydrostatic Pressure Testing by Using Inhibitors, Rev. Chim. 2021, Vol.72, p. 1.

15 EL BAKRI. Y., EL AOUFIR. Y., BOURAZMI. H., HARMAOUI. A., SEBHAOUI. J., TABYAOUI. M., GUENBOUR. A., OUDDA. H., LGAZ. H., EL HAJJAJI. F., BEN ALI. A., RAMLI. Y. ESSASSI. E.M, Corrosion control of carbon steel in phosphoric acid by 6-methyl-7H-1,2,4triazolo[4,3-b][1,2,4]triazepine-8(9H)-thione: Electrochemical studies , J. Mater. Environ. Sci. 2017 Vol. 8, P.2657.

16. A. M. ABDEL-GABER, H. T. RAHAL, F. T. BEQAI, Eucalyptus leaf extract as a eco-friendly corrosion inhibitor for mild steel in sulfuric and phosphoric acid solutions, Int. J. Ind. Chem.2020. vol.11, p. 123.17. S. DATTA, J. BISWAS, S. BHATTACHARYA, How does spacer length of imidazolium gemini surfactants control the fabrication of 2D-Langmuir films of silver-nanoparticles at the air-water interface?, J. Colloid Interface Sci., 2014, vol.430, p.85.

17.ZANA. R, Adv Colloid Interface Sci. Dimeric and Oligomeric Surfactants. Behavior at Interfaces and in Aqueous Solution: A Review ,2002, vol. 97, p.205.

18. ZANA.R, BENRRAOU.M, RUEFF. R, Alkanediyl-alpha., omega-bis(dimethylalkylammonium bromide) surfactants. 1. Effect of the spacer chain length on the critical micelle concentration and micelle ionization degree, Langmuir., 1991, vol.7, P. 1072.

19. AKBAR. J, TAVAKOLI. N, MARANGONI. D.G, WETTIG. S.D, Mixed Aggregate Formation in Gemini surfactant/1,2-dialkyl-sn-glycero-3-phosphoethanolamine Systems

J. Colloid Interface Sci., 2012, vol.377, p.237.

20.S. DATTA, J. BISWAS, S. BHATTACHARYA, How does spacer length of imidazolium gemini surfactants control the fabrication of 2D-Langmuir films of silver-nanoparticles at the air-water interface?, J. Colloid Interface Sci., 2014, vol.430, p.85.

21. B. LIU, J. LU, Y. XIE, B. YANG, X. WANG, R. SUN, Microwave-assisted Modification on Montmorillonite with Ester-Containing Gemini Surfactant and Its Adsorption Behavior for Triclosan J. Colloid Interface Sci., 2014, vol. 418, p. 311

22. RAIAH. K, DJALAB. A., HADJ-ZIANE-ZAFOUR. A, SOULA. B, GALIBERT. A.M, FLAHAUT. E., Study on Metal Nanoparticles Synthesis and Orientation of Gemini Surfactant Molecules Used as Stabilizer Colloid Surf. A: Physicochem. Eng. Aspects., 2015, vol. 469, p.107

23. FUCHS-GODEC. R, Effects of surfactants and their mixtures on inhibition of the corrosion process of ferritic stainless steel, Electrochim. Acta, 2009, vol. 54, p. 2171. 
24. FUCHS-GODEC. R, PAVLOVIC. M. G, Synergistic effect between non-ionic surfactant and halide ions in the forms of inorganic or organic salts for the corrosion inhibition of stainless-steel X4Cr13 in sulphuric acid, Corros. Sci, 2012, vol. 58, p.192.

25.AL SABAGH. A.M., KANDIL. N.GH, BADAWI. A. M, EL-SHARKAWY. H., Surface activity and thermodynamic of micellization and adsorption for isooctylphenol ethoxylates, phosphate esters and their mixtures with $N$-diethoxylated perfluorooctanamide Colloid Surf. A: Physicochem. Eng. Aspects, 2000, vol.170, p.127.

26. TOBSIN. T, BANGCHIT. P, SIRIKULLERTRAT. V., SUTTHIRUANGWONG. S, Influence of Sodium Dodecyl Sulfate on Corrosion Behavior of 304 Stainless Steel, Thammasat Int. J. Sc. Tech., 2010, vol.15, p.40.

27. HEGAZY. M.A, A novel Schiff base-based cationic gemini surfactants: Synthesis and effect on corrosion inhibition of carbon steel in hydrochloric acid solution, Corros. Sci., 2009, vol. 51, p.2610

28.WANG. L.W., LIU, Z.Y., CUI. Z.Y., DU. C.W., WANG. X.H, LI. X.G, In situ corrosion characterization of simulated weld heat affected zone on API X80 pipeline steel, Corros. Sci., 2014, vol. 85, p.401.

29. ABDEL HAMID. Z, Electrodeposition of cobalt-tungsten alloys from acidic bath containing cationic surfactants, Materials Letters. 2003, vol.57, p.2558

30. MIGAHED. M.A, AZZAM. E.M.S., AL-SABAGH. A.M, Corrosion inhibition of mild steel in $1 \mathrm{M}$ sulfuric acid solution using anionic surfactant, Mater. Chem. Phys., 2004, vol. 85, p. 273.

31. SZYMCZYK. K., JAŃCZUK. B , The adsorption at solution-air interface and volumetric properties of mixtures of cationic and nonionic surfactants, Colloid Surf. A: Physicochem. Eng. Aspects. , 2007, vol.293, p.39.

32. DATTA. M., LANDOLT. D., On the role of mass transport in high rate dissolution of iron and nickel in ECM electrolytes-I. Chloride solutions Electrochim. Acta, 1980, vol. 25, p. 1255.

33. KUMAR. S, BHARGAVA. P, SREEKANTH. V, BAJAJ. A, DESIGN, Design, Synthesis, and Physico-Chemical Interactions of Bile Acid Derived Dimeric Phospholipid Amphiphiles With Model Membranes J. Colloid Interface Sci., 2015, vol. 448, p. 398

34. EL-SABAGH. A.M, TANTAWY. N.S, NASSER. N.M, MISHRIF. M.R, Corrosion Inhibition Efficiency in Relation to Micellar Interaction Parameters of Cationic/Nonionic Surfactant Mixtures for Carbon Steel Pipelines in 1 M HCl Solution, J. Dispersion Sci. Technol., 2009, vol.30, p. 1411.

35. KIM. W., Tsuchiya, H, Fujimoto. S, Electrochemical Characterization of Passive Films on Ni-Based Alloys in Acidic and Neutral Solutions, Mater.Trans., 2015, vol. 56, p.593.

36. MORAD. M. S, KAMAL EL-DEAN. A. M, 2,2'-Dithiobis(3-cyano-4,6-dimethylpyridine): A new class of acid corrosion inhibitors for mild steel, Corros. Sci., 2006, vol.48, p. 3398.

37. GABREAB. E.M., HINDS. G, FEARN. S, HODGSON. D, MILLICHAMP. J, SHEARING. P.R, BRETT. D.J.L, An electrochemical treatment to improve corrosion and contact resistance of stainless steel bipolar plates used in polymer electrolyte fuel cells, Journal of Power Sources, 2014, vol.245, p.1014.

38. LU. K, TIAN. Z, GELDMEIER. J.A, Polishing effect on anodic titania nanotube formation, Electrochim. Acta., 2011. Vol. 56, p.6014.

39. MUSA. A. Y, KADHUM. A. A. H, MOHAMAD. A. B, TAKRIFF. M. S., On the inhibition of mild steel corrosion by 4-amino-5-phenyl-4H-1, 2, 4-trizole-3-thiol. Corros. Sci., 2010, vol. 52, p. 3331

40. FELHÖSI. I, KÁLMÁN. E, Corrosion protection of iron by $\alpha, \omega$-diphosphonic acid layer, Corros. Sci., 2005, vol. 47, p. 695

41. ATTA. A.M, EL-AZABAWY. O.E, ISMAIL. H.S, HEGAZY. M.A, Novel dispersed magnetite core-shell nanogel polymers as corrosion inhibitors for carbon steel in acidic medium Corros. Sci., 2011, vol. 53 , p. 1680 .

42. BENTISS. F, TRAISNEL. M, LAGRENEE. M, The substituted 1,3,4-oxadiazoles: a new class of corrosion inhibitors of mild steel in acidic media. Corros. Sci., 2000, vol. 42, p. 127. 
43. GE. H.H, ZHOU. G.D, WU. W. Q., Comparison of corrosion properties of passive films formed on phase reversion induced nano/ultrafine-grained 321 stainless steel, Appl. Surf. Sci., 2003, vol.211, p.321.

44. NEGM. N.A, KANDILE. N.G, BADR, E.A, MOHAMMED. M.A, Gravimetric and electrochemical evaluation of environmentally friendly nonionic corrosion inhibitors for carbon steel in $1 \mathrm{M} \mathrm{HCl}$, Corros. Sci, 2012, vol. 65, p. 94

45. TAHA, A. A. ABDEL RAHMAN, H. H., ABOUZEID, F. M., Effect of surfactants on the rate of diffusion controlled anodic dissolution of copper in orthophosphoric acid. Int. J. Electrochem. Sci.. 2013, vol. 8, p. 6744.

46. ABD EL REHIM. S.S, AMIN. M.A, MOUSSA, S.O, ELLITHY. A.S, The corrosion inhibition of aluminum and its copper alloys in $1.0 \mathrm{M} \mathrm{H} 2 \mathrm{SO} 4$ solution using linear-sodium dodecyl benzene sulfonate as inhibitorMaterials Chemistry and Physics., 2008, vol. 112, p.898.

47. BAGHALHA. M, AHMADI. M.K, Copper corrosion in sodium dodecyl sulphate solutions and carbon nanotube nanofluids: A modified Koutecky-Levich equation to model the agitation effect, Corros. Sci, 2011, vol. 53, p.4241.

48. FOUDA. A.S, AL-SARAWY. A.A, AHMED. F.S, EL-ABBASY. H.M, Corrosion inhibition of aluminum 6063 using some pharmaceutical compounds, Corros. Sci., 2009, vol. 51, p.485.

49.SOLOMON. M.M, UMOREN. S.A, UDOSORO. I, UDOH. A.P, Inhibitive and adsorption behaviour of carboxymethyl cellulose on mild steel corrosion in sulphuric acid solution, Corros. Sci., 2010, vol.52, p.1317.

$\overline{\text { Manuscript received: } 11.05 .2021}$ 